\title{
Are accounting academics culturally intelligent?: An empirical investigation
}

\author{
Meredith Tharapos, \\ Brendan T. O'Connell, \\ Steven Dellaportas \\ School of Accounting, \\ RMIT University, \\ Melbourne, \\ Victoria 3000, \\ Australia \\ Ilias Basioudis \\ Accounting Group, \\ Aston Business School, \\ Aston University, \\ Birmingham, \\ B4 7ET, \\ UK
}




\title{
Are accounting academics culturally intelligent?: An empirical investigation
}

\begin{abstract}
Cultural diversity within accounting university classrooms creates a number of educational challenges that have been little investigated. This study draws on the theoretical framework of cultural intelligence (CQ), which is new to accounting research, to enhance understanding of the intercultural capabilities of accounting academics. CQ is comprised of four interrelated capabilities: metacognitive, cognitive, motivational and behavioural. The previously validated cultural intelligence scale (CQS) survey was used to identify $C Q$ levels and results were compared to demographic variables and other factors in order to explain differences. The results indicate that accounting academics display levels of $C Q$ at the lower end of comparable studies on other professionals. Results also show that academics who have lived abroad for longer than one year and who have taught transnationally in Southeast Asia are likely to possess significantly higher levels of total $C Q$. Female accounting academics are more likely to possess higher levels of behavioural $C Q$ indicating a propensity to more easily adapt their behaviour in culturally diverse situations. This paper contributes to the growing literature on $C Q$ by increasing our understanding of the antecedents that influence $C Q$ levels in the area of international experience, through the examination of the potential impact of overseas teaching experiences and overseas residency. Furthermore, this study introduces and examines new measures capturing the breadth and depth of international experience; that of long-term overseas residency and cultural distance.
\end{abstract}

Key words: cultural intelligence, accounting, international experience, cultural distance, higher education 


\section{Are accounting academics culturally intelligent?: An empirical investigation}

\section{Introduction}

Universities 'constitute one of the most diverse collections of individuals that may be encountered by another group of social perceivers' (Spencer-Rogers, 2001, p. 640), creating an environment that contains a level of diversity rarely found elsewhere (Harrison, 2012). It is this environment within which faculty must interact and operate on a daily basis. While cultural diversity brings richness and a breadth of perspectives, it also creates the potential for conflict, misinterpretation and marginalisation (Kelly, 2008; Le Roux, 2001). This is no more evident than in today's world with the mass flow of cross-border refugees fleeing political persecution and poverty, the upsurge in terrorism, political and economic instability with Brexit in the UK, the arrival of the 'Trump era' in the US, and an increasing emphasis on nationalism and xenophobia in some nations in Europe and Asia (Altbach \& de Wit, 2017; Rachman, 2017). The broader societal trends of an increasingly globalised world not only influences the geographical mix within classrooms, but also the manner in which 'students, academics and universities interact with each other and with the world' (Altbach \& de Wit, 2017). Diversity in higher education created by internationalisation raises the question as to the capacity of academics to adapt and operate within a complex multicultural work environment. Some individuals are able to move seamlessly across cultural boundaries, while others struggle with the underlying complexities of cultural diversity (Harrison, 2012; Teekens, 2003). Yet there is a paucity in knowledge as to why. A study examining cross-cultural capabilities in academe is both timely and necessary.

Cultural intelligence (CQ), defined as the 'capability of an individual to function effectively in situations characterised by cultural diversity' (Ang \& Van Dyne, 2008, p.3), presents a unique framework to examine cross-cultural capabilities (Earley, Ang, \& Tan, 2006). CQ is comprised of four interrelated components (metacognitive, cognitive, motivational and behavioural) of equal importance (Earley \& Ang, 2003). Thus it follows that a 'culturally intelligent individual possesses the necessary background knowledge of a particular culture, as well as the motivation to learn about new cultures and create new mental frameworks in order to expand his or her behavioral repertoire' (Groves, Feyerherm, \& Gu, 2015, p. 212). According to Ang and Van Dyne (2008), CQ is malleable and can be developed over time through intercultural experiences, travel and appropriate training.

Using cultural intelligence (CQ) as the informing theoretical framework, the purpose of this study is to examine the cross-cultural capabilities of accounting academics and to understand 
the factors that affect the development of their $C Q$. In particular, this study will examine the levels of $C Q$ exhibited by accounting academics and the factors that might explain differences in their levels of CQ. CQ studies in education have utilised students in various countries as their frame of reference (see for example, Ang, Van Dyne, Koh, Ng, Templer, Tay, \& Chandrasekar, 2007; Lin, Chen, \& Song, 2012; T. Moon, 2010; Shannon \& Begley, 2008). However, $C Q$ has yet to be explored in relation to academics operating in the culturally diverse environments present in today's universities as a result of increasing levels of international student mobility (Australian Government, 2016). International education activities generate significant revenue streams for host countries (Universities Australia, 2017; Universities UK, 2017) and cultural experience is becoming an increasingly important factor in country selection for international students (ICEF Monitor, 2017). This is of heightened importance to countries like the UK with the introduction of the Teaching Excellence Framework and quality ranking systems to promote and reinforce the sector's reputation globally (Higher Education Academy, 2017). Host countries who are successful in engaging and retaining international students by providing rewarding cross-cultural experiences will more than likely be successful in rankings outcomes.

The accounting profession has highlighted the importance and need for greater cultural awareness (CGMA, 2016; GAA, 2016; ICAEW, 2015b). Carter and Spence (2014), drawing on Bourdieu's (2012) notion of habitus and different forms of capital, contend that contemporary partners in large accounting firms 'must relentlessly perform and display a much more meritocratically acquired configuration ... of linguistic, social, and cultural capital' ( $p$. 976), which serves the public interest, rather than merely employing a commercial focus that privileges client interests and revenue generation (Spence \& Carter, 2014). A broader set of capitals and a greater focus on skills, such as cross-cultural skills, is required. However, the discipline of accounting in both professional and educational contexts, and academia in general, are surprisingly absent from the $C Q$ literature, despite its significant relevance to the accounting and educational professions in the current global climate. The present study contributes to $C Q$ literature by examining $C Q$ within the accounting discipline, thereby addressing this lacuna.

This study makes two major contributions to $C Q$ scholarship. First, the study makes a significant contribution to $C Q$ scholarship by extending knowledge of the antecedents of $C Q$. A major focus of prior research examining the antecedents of $C Q$ has been in the area of international experience, both work-related and non-work-related, although the results have been mixed (Crowne, 2008; H. K. Moon, Choi, \& Jung, 2012; Shannon \& Begley, 2008; Tarique \& Takeuchi, 2008; Tay, Westman, \& Chia, 2008). This study further interrogates 
international experience to better understand its influence on $C Q$ in two ways. First, by examining work-related international experience pertinent to academic accountants alongside the notion of cultural distance, in order to explain the mixed findings obtained in previous studies. Second, by introducing a new measure of international experience, that of long-term overseas residency, to examine the impact of a long-term and potentially deeper international experience. This has not previously been examined in $C Q$ scholarship. An extended understanding of international experience also builds on the management literature relating to the influence of international work experiences (see, for example, Dragoni, Tesluk, VanKatwyk, In-Sue, Moore, \& Hazucha, 2014; McCall \& Hollenbeck, 2002). Whereas such literature is focused on the influence of cultural distance on managers' strategic thinking, this study examines the influence of cultural distance on the development of academics' $\mathrm{CQ}$. In sum, our study develops a new international experience variable, that of long-term overseas residency, and examines the notion of cultural distance to explain the mixed findings obtained in previous studies in relation to international experience and $C Q$. Understanding the factors that lead to higher levels of $C Q$ is of paramount importance to the accounting profession, universities, and academics as individuals and team members functioning in environments with a level of cultural diversity rarely found elsewhere.

Second, this study applies the concept of CQ to the discipline of accounting, which has not been previously examined in professional or educational contexts. Research on CQ has made a major contribution to intercultural scholarship since its conceptualisation in 2003, with empirical research having intensified since the CQS scale was established and validated in 2007 (Ang et al., 2007). The CQS has been used in many studies, and the reliability of the scales has been found to be high across samples (Ang et al., 2007; Van Dyne, Ang, \& Koh, 2008); time (Shokef \& Erez, 2008; Van Dyne et al., 2008), cultures (Ang et al., 2007; Shannon \& Begley, 2008; Van Dyne et al., 2008); and both international and domestic culturally diverse groups (Kim, Kirkman, \& Chen, 2008; Shokef \& Erez, 2008). Existing research has examined $\mathrm{CQ}$ among a variety of cohorts including the military (Sahin, Gurbuz, \& Koksal, 2014), international managers (Ang et al., 2007), non-skilled workers (Chen, Lin, \& Sawangpattanakul, 2011) and students (Lin et al., 2012; Shannon \& Begley, 2008; Van Dyne et al., 2008), yet there remains a paucity of research in accounting. The significance of $C Q$ among the accounting profession (professional associations and large accounting firms) is evident by the increasing investment of resources and workshops preparing members and staff for cross-cultural activities (AICPA, 2016; CPA Australia, 2014; Deloitte, 2015; EY, 2013; ICAEW, 2015a; KPMG, 2012). This research is a timely response to calls for research which contribute to the adoption of formal structures and mechanisms aimed at the reduction of culturally insensitive practices (Huang, Fowler, \& Baskerville, 2016), to assist in moving 
'professional values in accounting firms from favouring economic interests of the "white collared" partners back towards the wider "public good" principles' (Baskerville, Jacobs, Joannides de Lautour, \& Sissons, 2016, p. 1267).

While international education is present in many academic disciplines, the focus on accounting academics was considered appropriate for two reasons. First, the accounting discipline globally has grown and is significantly impacted by the burgeoning number of international students (BIS, 2013; IIE, 2015; Tadros \& King, 2014). Second, the accounting discipline in countries such as the UK, US and Australia has historically been at the forefront of much of the transnational teaching, particularly in Southeast Asia (Cooper \& Adams, 1997; Yang, 2012). Thus, academics in charge of accounting classrooms containing an ever-changing mix of cultures, both domestically and transnationally, are faced with significant challenges. Australia was selected as the country in which to undertake this study as it is currently one of the world's leading suppliers of international education (Guthrie \& Parker, 2014). Furthermore, Australia has increasingly recruited academics from countries throughout the world, reflecting its multicultural history and perspective (O'Connell, Carnegie, Carter, Helliar, Watty, Hancock, \& DeLange, 2015). Even though our study is set in the Australian accounting academic context, the findings have relevance beyond Australia and the accounting discipline, as this phenomenon is by no means unique to the Australian accounting academic setting.

The data for this study was collected via a survey utilising the Cultural Intelligence Scale (CQS) developed by Ang et al. (2007) to measure the level of CQ of accounting academics. The survey was distributed to the entire population of full-time accounting academics in Australia. The findings indicate that accounting academics have lower average CQ compared with other professional groups. This is surprising and concerning given the internationalisation of accounting. Both overseas residency and transnational teaching in Southeast Asia were found to be significant and positively associated with the $C Q$ levels of accounting academics. Furthermore, gender was also found to be significant, with female accounting academics being more likely to possess higher levels of behavioural $C Q$.

The remainder of this paper is organised as follows. Section 2 describes the theoretical framework of cultural intelligence and prior research conducted using this framework. The research design is explained in section 3 , and the results and discussion are presented in section 4 . The final section contains the conclusions arising from the study, an indication of how the findings may be utilised, the contributions to $C Q$ scholarship, and suggestions for future research. 


\section{Cultural intelligence - theoretical framework and prior research}

\subsection{Theoretical framework}

$C Q$, conceptualised by Earley and Ang in 2003, is based on the theory of multiple loci of intelligence developed by Sternberg and Detterman (1986). Emotional intelligence, defined as the 'capacity to reason about emotions, and of emotions to enhance thinking' (Mayer, Salovey, \& Caruso, 2004, p. 197), 'encapsulates the ability to organize, recognize, use, and manage emotions and people' (Daff, de Lange, \& Jackling, 2012, p. 627). Emotional intelligence is posited to assist accountants with enhanced performance in functions such as decision making, leadership, team building and client relations (Cook, Bay, Visser, Myburgh, \& Njoroge, 2011). While studies have been conducted using emotional intelligence in accounting research (for example; Abraham, 2006; Bay \& McKeage, 2006; Chia, 2005; Cook et al., 2011; Daff et al., 2012; McPhail, 2004; Nicholls, Wegener, Bay, \& Cook, 2012), CQ is yet to be explored in this context. Emotional intelligence presumes 'people are familiar with their own culture and that they (often subconsciously) use familiar situations as a way to interact with others. Cultural intelligence picks up where emotional intelligence leaves off - it involves dealing with people and situations in unfamiliar surroundings' (Tan, 2004, p. 19). CQ is comprised of four interrelated capabilities of equal importance; metacognitive, cognitive, motivational and behavioural (Ang \& Van Dyne, 2008; Ng \& Earley, 2006), as shown in Figure 1.

[Insert Figure 1 about here]

Metacognitive CQ involves analysing one's own thought processes using cultural knowledge to understand and solve problems when faced with a different cultural situation (Ang \& Van Dyne, 2008). It is concerned with higher order cognitive processes, challenges rigid reliance on culturally bound assumptions, and emphasises strategy as the lynchpin between knowledge of cultural issues and understanding how to use that knowledge to be more effective in culturally diverse settings (Triandis, 2006). Cognitive CQ refers to the knowledge of cultural norms, values, practices and conventions associated with different societies, along with their differences, that have been acquired through education and personal experiences (Ang \& Van Dyne, 2008). Cultural values and norms refer to the 'varying ways cultures approach things like time, authority, and relationships' (Ang, Van Dyne, \& Tan, 2011, p. 584). This knowledge is particularly important when making decisions in a different cultural environment (Ang et al., 2007) and is the component typically emphasised in traditional crosscultural training courses (Ang \& Van Dyne, 2008). Motivational CQ refers to an individual's level of interest, drive and energy to function and interact effectively in culturally diverse situations and to persevere through the inevitable challenges and conflicts (Ang \& Van Dyne, 
2008). Those with higher motivational $C Q$ are drawn to cross-cultural situations as they place great importance on their value and are confident they will be able to deal with the inevitable challenges. Behavioural CQ refers to an individual's ability to enact a wide range of behaviours when dealing with people from different cultures and includes both verbal (accent, tone and expressiveness) and non-verbal behaviour (body language, gestures and facial expressions), and speech acts (the exact words and phrases used) (Ang \& Van Dyne, 2008; Livermore, 2011; Van Dyne, Ang, Ng, Rockstuhl, Tan, \& Koh, 2012). Those with higher behavioural CQ exhibit behavioural flexibility, overcoming the natural tenancy to revert to habitual behaviour. Each of these components is of equal importance in assisting an individual to gain a deeper understanding during, and to improve the outcome of, intercultural dealings (Earley \& Ang, 2003). Thus it follows that individuals with high levels of all four components of $C Q$ will 'have a desire to continually translate cultural knowledge to generate strategies that will aid in exhibiting appropriate verbal and non-verbal behaviours' (Engle \& Crowne, 2014, p. 33).

While CQ has become a burgeoning area of multidisciplinary scholarship (Ott \& Michailova, 2016), there have been few criticisms of this construct (Elenkov \& Manev, 2009). Matsumoto and Hwang (2013) reviewed ten methods of assessing cross-cultural competence, extensively comparing their content and the constructs on which they were based, and evaluated the reliability and validity of their related assessments. They concluded that the CQS is one of three assessments that 'have the most promising evidence for assessing $3 \mathrm{C}$ [cross-cultural competence]' (Matsumoto \& Hwang, 2013, p. 867). Furthermore Hampden-Turner and Trompenaars (2006), in their critical examination of CQ as another cultural factor at a macro level, concluded that $C Q$ is a distinct ability that can be said to exist. However, Bucker, Furrer, and Lin (2015) question the validity of the four component model of $C Q$, arguing that findings from their study demonstrate a better fit with a two component model. Ward, Fischer, Lam, and Hall (2009) also query whether CQ is sufficiently distinct from emotional intelligence, and Blasco, Feldt, and Jakobsen (2012) contend that CQ can be acquired through training. Furthermore, it is acknowledged that the CQS is a self-assessed questionnaire and thus carries with it all the usual limitations associated with such methods. In light of the comments made by Gelfand, Imai, and Fehr (2008), stating that the concept of CQ 'offers parsimony, theoretical coherence, and precision that is unprecedented in the cultural competency literature' (p.385), this study drew on the theoretical framework of $C Q$ as a lens through which to examine the cross-cultural competencies of accounting academics.

\subsection{CQ and international experience}

Researchers have empirically examined $C Q$ in relation to emotional intelligence and found $C Q$ to be related but distinct from emotional intelligence (Ang et al., 2007; Lin et al., 2012; T. Moon, 2010; Rockstuhl, Seiler, Ang, Van Dyne, \& Annen, 2011; Van Dyne et al., 2008) and a 
predictor of performance in intercultural settings over and above emotional intelligence (Rockstuhl et al., 2011). CQ has also been examined as a predictor of a wide range of cognitive, psychological and behavioural outcomes. For example, CQ has been found to consistently predict performance outcomes beyond personality dimensions (Rockstuhl et al., 2011; Sahin et al., 2014). It has been found to be positively related to cultural adjustment (Lin et al., 2012; H. K. Moon et al., 2012; Ramalu, Rose, Kumar, \& Uli, 2010; Wu \& Ang, 2011) and global leadership performance (Groves \& Feyerherm, 2011; Keung \& Rockinson-Szapkiw, 2013). High $C Q$ amongst team members has been found to expedite team integration (Flaherty, 2008) and a negative relationship has been detected between CQ and culture shock (Chen et al., 2011). Personality has been found to exhibit meaningful relationships with $C Q$ (Ang, Van Dyne, \& Koh, 2006). In particular, the personality trait 'openness to experience', that is the tendency to be imaginative, creative, broad-minded, intelligent, and adventurous (McCrae, 1996), is positively related to all four CQ components (Ang et al., 2006), with all six sub-factors (intellectual efficiency, ingenuity, curiosity, aesthetics, tolerance, and depth) relating significantly to CQ (Oolders, Chernyshenko, \& Stark, 2008). This finding provides further validity of $C Q$, as it would be expected that both $C Q$ and openness to experience would be related, as they both pertain to novel situations ( $\mathrm{Ng}$, Van Dyne, \& Ang, 2012). Individuals who are open to new experiences are more willing to move beyond the familiar to the new and unfamiliar (Ones \& Viswesvaran, 1997), more readily accept differences between cultures (Bhagat \& Prien, 1996), and are less likely to adopt racial stereotypes and other biases (Flynn, 2005).

The majority of research examining the antecedents of $C Q$ has explored both work-related international experience (such as business trips and expatriate assignments) and non-workrelated international experience (such as trips for education or personal purposes). In relation to work-related international experience, Shannon and Begley (2008) report that the number of countries in which the individual has worked is positively related to metacognitive $C Q$ and motivational CQ. Crowne (2008) shows that work-related international experience is positively related to all components of $C Q$ except motivational CQ. Tay et al. (2008) studied short-term business travellers, finding that the length of work-related international experience as measured by the average of firstly, the proportion of work time spent outside the home country, and secondly, the product of the number of business trips and average duration of business trips made in the year, relates only to cognitive CQ. It should be noted that the Tay et al. (2008) study utilises only eight of the 20 items from the CQS to measure CQ. Examining non-workrelated international experience, Tarique and Takeuchi (2008) report that the number of countries visited is positively related to all four components of $C Q$, although the length of stay, as measured by summing the number of days of each reported experience, moderates the 
relationship between the number of international experiences and metacognitive $C Q$, and the relationship between the number of international experiences and motivational $\mathrm{CQ}$. Crowne (2008) found the number of countries visited for educational purposes is positively related to cognitive $C Q$ and behavioural $C Q$, and the number of countries visited for vacation purposes is positively related only to motivational CQ. Surprisingly, Crowne (2008) in her study found 'currently living outside an individual's country of citizenship' (although there is no time period attached to this measure) negatively impacts behavioural CQ. Interestingly, in H. K. Moon et al.'s (2012) study of Korean expatriates, international non-work-related experience rather than their work-related experience predicts CQ. H. K. Moon et al. (2012) posits that individuals undertaking work-related international trips tend to focus the vast majority of their time and energy on business issues at hand, rather than on understanding and learning the new culture within which they are required to operate. Crowne (2008) suggests that an individual undertaking a long-term international experience has a greater opportunity to gain a detailed cultural understanding through extensive exposure than does someone on a short-term trip. Through meaningful interactions with locals, an individual experiences an increased sense of engagement (Osland \& Osland, 2006) and short-term trips do not easily lend themselves to these opportunities (Oddou, Mendenhall, \& Ritchie, 2000). However, Engle and Crowne (2014) and Wood and St. Peters (2013) found that students' participation in structured shortterm cross-cultural study tours, which include modest pre-trip preparation, is associated with higher $C Q$. It should be noted that the cross-cultural study tours in these studies were purposefully designed to facilitate interaction with locals from the host country.

In sum, the measure used to capture international experience has been largely confined to the number of international experiences, along with rudimentary attempts to capture the length of short-term international experiences. This has resulted in mixed findings about how international experience is related to total $C Q$ and each of the components of $C Q$. The issue of long-term international experience has not been examined. Furthermore, Lee and Sukoco (2010) and Engle and Crowne (2014) have called for exploration of international experience in the area of cultural distance (Hofstede, Hofstede, \& Minkov, 2010; House, Hanges, Javidan, Dorfman, \& Gupta, 2004). There have been no studies conducted to date examining international experience and $C Q$ in relation to the different types of cultural environments visited - the present study provides insights into this lacuna in understanding. The pertinent issue with international experience may not be the experience itself, but rather the quality of the experience and one's receptiveness to the experience. Dragoni et al. (2014), in a study of Anglo upper level leaders, found international work-related experiences ${ }^{1}$ positively relate to the strategic thinking competency of global leaders, particularly if the international experience

\footnotetext{
${ }^{1}$ Dragoni et al. (2014) did not examine CQ.
} 
occurs in culturally distant host environments. However, Dragoni et al. (2014) caution that the results of their study are not generalisable to average upper level leaders from non-Anglo countries, or indeed the general population. The present study focuses on extending understanding of the antecedents of $\mathrm{CQ}$, particularly in the area of international experience. Specifically, this study develops a new international experience variable, that of long-term overseas residency, and examines the notion of cultural distance.

In addition to international experience and openness to experience, other identified antecedents of $C Q$ include foreign language ability, which is positively associated with $C Q$ levels (Shannon and Begley, 2008; Harrison, 2012). In learning another language, parallel learning about its culture tends to occur (Alon and Higgins, 2005; Harrison, 2012). Cultural exposure in all forms (Crowne, 2013), multicultural upbringing and an international orientation (Harrison, 2012), and participation in short-term study tours (Wood and St. Peters, 2013) are associated with higher CQ. MacNab and Worthley (2012) found individuals with higher levels of self-efficacy were more likely to improve their $C Q$. Men have been found to have higher levels of ethnocentrism than women (Harrison, 2012), but no gendered differences have been detected for $\mathrm{CQ}$.

In the educational context, students' $C Q$ has been studied in several countries but not that of educators. For example, CQ was predicted by openness to experience in a study conducted at a Singaporean university (Ang et al., 2006); general self-efficacy in a study of university students in the US and Australia (MacNab \& Worthley, 2012); and a short-term study abroad experience in a study conducted at an American university (Engle \& Crowne, 2014). In a study conducted at a British university, Harrison (2012) identified the following predictors of $C Q$; agreeableness and openness, a multicultural upbringing, foreign language capabilities and an international orientation. In their study of international students in Taiwan, Lin et al. (2012) found that $C Q$ had a positive effect on cross-cultural adjustment after controlling for gender, age, previous overseas experience, English ability and host-country language ability. To the authors' knowledge, there is no published evidence examining CQ with respect to academics who teach in the culturally diverse classrooms of the contemporary university. Education researchers have called for an increased awareness of cultural differences in teaching and learning (Joy and Kolb, 2009), and the development of CQ in academics (Gokulsing, 2006; Griffer \& Perlis, 2007; Tomalin, 2007). Furthermore, as previously mentioned, there are no published studies examining $C Q$ within the discipline of accounting, despite the practical realities of globalisation in the domain. This study addresses these deficiencies in understanding. 


\section{Research design}

\subsection{Survey instrument}

The survey instrument consisted of two sections ${ }^{2}$. Section 1 contained the 20-item CQS, as developed by Ang et al. (2007). Respondents were required to rate on a seven-point Likert scale (strongly disagree $=1$, strongly agree $=7$ ) the extent to which each item in the CQS reflected their own capabilities. Section 2 contained questions on the demographics and background of participants, including university location, gender, age, academic position, teaching experience and qualifications. Drawing on the findings of Tarique and Takeuchi (2008) and Harrison (2012) that foreign language abilities predict CQ, respondents were asked how many languages, other than English, they spoke fluently. Based on the findings of Baskerville, Wynn-Williams, Evans, and Gillett (2014) that the use of 'first language' is a justifiable proxy for ethnicity in accounting research, respondents were also asked whether English was their first language.

Prior research on measuring work-related and non-work-related international experience has relied on simplistic measures such as number of international experiences (Tarique \& Takeuchi, 2008; Lee \& Sukoco, 2010; H. K. Moon et al., 2012; Engle \& Crowne, 2014) and length of international experience (Tarique \& Takeuchi, 2008; Tay et al., 2008; Lee \& Sukoco, 2010). In an attempt to capture a more multifaceted perspective, Crowne $(2008 ; 2013)$ used the number of countries visited as a measure of the breadth of international experience. This study expanded on the multifaceted approach adopted by Crowne $(2008 ; 2013)$ by examining the depth and breadth of work-related international experience pertinent to accounting academics. Participants in this study were asked how many times they had taught transnationally, as a measure of the depth of work-related international experience, and the number of countries in which they had taught transnationally, together with the names of those countries, as a measure of the breadth of work-related international experience. Additionally, this study used a new measure of international experience, that of overseas residency, to gain an understanding of the impact of a deeper international experience on $C Q$ levels. Using Puccino's (2007) definition of a long-term international experience, that of greater than one year, participants in the present study were asked to indicate whether they had resided in a country other than Australia for a continuous period exceeding twelve months. If participants answered yes to this question, they were asked to specify the name of the country/countries, the length of residence, and the years in which they were an overseas resident.

\footnotetext{
${ }^{2}$ The full survey instrument is available from the corresponding author on request.
} 


\subsection{Sample selection and survey administration}

The entire population of full-time Australian accounting academics were invited to participate in the survey. In order to compile a list of accounting academics in Australia, the staff listings of business schools and faculties on the websites of all 38 Australian public universities, and one private university, were scrutinised to identify academics employed full-time and listed as teaching accounting (a method previously employed by Samkin and Schneider, 2014). Adjunct professors, emeritus professors, research fellows and doctoral students were excluded due to potential access difficulties given the nature of their roles. Sessional (part-time) staff were also excluded as they tend to be a transient population that are difficult to identify, and often teach across several universities. This resulted in a list of full-time accounting academics compiled for each university, which was forwarded to one person on the list for confirmation, particularly if it was suspected that the university website was not current given academic staff movements known to the authors. A population of 771 full-time accounting academics was identified from 39 universities.

Online administration of the survey was considered to be the most reliable method of reaching the identified population for two reasons; the geographical dispersion of universities in Australia, and the administration of the survey between teaching semesters when academics could be located at a place other than their university of employment. An invitation to participate and a Participant Information Sheet were emailed to all members of the population, with the exception of academics from one university (seven academics) whose email addresses were not available on the university website and were not further contacted. Two reminder emails were sent at two-weekly intervals. Automatic replies were received from 19 academics on extended leave during and beyond the period of the survey, thus reducing the population of academics available to undertake the survey to 745 . In order to increase the response rate, printed copies of the questionnaire and Participant Information Sheet were distributed to delegates attending the Accounting and Finance Association of Australia and New Zealand (AFAANZ) Annual Conference in Perth in July 2013. The AFAANZ Annual Conference was selected as it is the leading conference for accounting academics in Australia, with an attendance of approximately 350-400 delegates (AFAANZ, 2012, 2014). The conference delegates were invited to complete the questionnaire only if they had not already done so online. A total of 253 completed responses (218 online, 35 hard copies) were received, representing a response rate of $34 \%$. Responses from online and hard copy questionnaires were compared; no statistically significant differences were found and responses were therefore aggregated during the analysis stage. In addition, responses from pre-deadline respondents were compared with responses received following the first and second reminders. No statistically significant differences were noted, suggesting there is a 
lack of a non-response bias (Rogelberg \& Stanton, 2007). Furthermore, as noted in the following section, the demographics of accounting academics who responded to this survey correspond with information available on university websites and those reported in prior studies (Cappelletto, 2010; O'Connell et al., 2015; Samkin \& Schneider, 2014).

\section{Results and discussion}

\subsection{Sample description}

A summary of the demographics of the survey respondents is provided in Table 1. Just over half the respondents were male (53.4\%), the largest groups of respondents were aged 45-54 years $(37.9 \%)$ and 55 years and over $(28.9 \%)$, and were employed as lecturers $(40.7 \%)$. Almost half $(48.6 \%)$ of the respondents had more than 15 years tertiary teaching experience, and two thirds (66\%) did not hold a formal teaching qualification (e.g. Graduate Certificate in Tertiary Teaching and Learning). These demographics accord with those reported in prior studies (Cappelletto, 2010; O'Connell et al., 2015; Samkin \& Schneider, 2014) and attest to the aging nature of the accounting academic workforce (Hancock, Howieson, Kavanagh, Kent, Tempone, \& Segal, 2009), which is a global issue (EUI, 2015).

\section{[Insert Table 1 about here]}

Two thirds $(66.8 \%)$ of respondents had taught transnationally, $22.1 \%$ having taught on $1-3$ occasions, and $30.4 \%$ having taught transnationally on more than 10 occasions. Their transnational teaching was concentrated in three countries, Singapore, Hong Kong and Malaysia, with the majority of respondents who had taught transnationally having taught in only 2-3 countries. English was the first language for $72.3 \%$ of respondents and $57.3 \%$ did not fluently speak a language other than English. More than half of the respondents $(54.5 \%)$ had resided overseas for a continuous period exceeding twelve months. These countries were quite diverse, and extended across Asia, Europe, Africa, the Americas and the Pacific region.

\subsection{Confirmatory factor analysis}

Reliability and validity testing was carried out as follows; first, exploratory factor analysis was undertaken for all items, resulting in four component solutions consistent with Ang et al. (2007). Second, confirmatory factor analysis (CFA) was performed where the specified model consisted of four metacognitive $C Q$ items, six cognitive $C Q$ items, five motivational $C Q$ items and five behavioural $C Q$ items loading onto their corresponding $C Q$ components, and all $C Q$ components loading onto an overall CQ construct. This second-order CQ factor model (Model M1) had sufficient fit $(\chi 2=451.10(163 \mathrm{df}), p=.000$, comparative fit index $(\mathrm{CFI})=0.884$ rootmean-square error of approximation $($ RMSEA $)=0.084)$, although some of the fit indices were slightly below the criteria cut-offs suggested by Hu and Bentler (1999). 
Further, in order to examine the relative fit of our second-order CQ factor model, we compared this model with two alternative nested models which include a single-factor model (Model M2), and a four-factor correlated model representing a first-order CQ factor model (Model M3). The fit indices for our main factor model (Model M1) reported in the preceding paragraph are found to be superior to that of the two alternative measurement models (Models M2 and M3). Specifically, the following chi-square differences demonstrate that Model M1 possesses better fit than both Models M2 and M3: $\Delta \chi 2$ (M2 vs. M1) $=500.8$, dfD $=8, p<.0001$ and $\Delta \chi 2$ (M3 vs. M1) $=28.2, \mathrm{dfD}=1, p<.0001]$. These comparisons show that we can confidently conclude that the second-order CQ factor model reported in this study is the most strongly-supported model.

Variance inflation factor (VIF) scores were also calculated. All untabulated VIF scores were below the cut-off of 2.4 suggested by Hair, Black, Babin, and Anderson (2010), confirming the results are unlikely to be confounded by collinearity. Following assessment of the underlying dimensionality, the multi-item scales were assessed for their reliability. In this study, the overall CQS had high reliability ( $\alpha=0.922)$, as did its four components: metacognitive CQ $(\alpha=0.841)$, cognitive $C Q(\alpha=0.859)$, motivational $C Q(\alpha=0.794)$ and behavioural $C Q(\alpha=0.823)$, as all values were above the 0.7 cut-off point suggested by Kline (1999).

\subsection{Level of CQ}

Consistent with previous studies (see, for example, Keung \& Rockinson-Szapkiw, 2013), an average score was calculated for each CQ component to ensure an equal weighting $(25 \%)$ when calculating the total $C Q$ score. Thus, the average scores for the individual components of $C Q$, and total $C Q$, can range from 1 to 7; a higher score implies possessing higher $C Q$. The means from this study for total $C Q$ and each of the four $C Q$ components are shown in Table 2. This table shows that the mean $C Q$ score of accounting academics is 4.98 , and they have rated themselves most highly on items in the CQS relating to metacognitive $C Q$ (mean=5.34), then motivational $\mathrm{CQ}$ (mean=5.33), followed by behavioural $\mathrm{CQ}$ (mean=5.06) and finally cognitive $C Q$ (mean=4.19). Of the four components, metacognitive $C Q$ recorded the highest mean, indicating that accounting academics rank themselves relatively highly in relation to their ability to plan, analyse and check strategies in relation to cross-cultural encounters. It appears that accounting academics can formulate appropriate strategies for use in culturally diverse situations and have the ability to effectively operationalise them. Motivational $C Q$ recorded a mean score slightly below that of metacognitive $C Q$, indicating that accounting academics also rate themselves highly in relation to their level of interest, drive and energy to function and interact effectively in culturally diverse situations. This indicates that accounting 
academics are drawn to cross-cultural situations and are confident in their ability to manage any associated challenges.

[Insert Table 2 about here]

The data in Table 2 shows that cognitive CQ recorded the lowest mean and the largest standard deviation, with scores recorded at both the minimum of 1 and the maximum of 7 . This indicates that accounting academics do not rate themselves highly on the capability of possessing knowledge of cultural norms, values, practices and conventions associated with different societies. This is of particular concern as it is cultural knowledge (cognitive CQ) that informs the formulation of appropriate strategies for use during intercultural encounters (metacognitive CQ). Moreover, a lack of cultural knowledge can lead to the sort of prejudices, biases and ethnocentric generalisations that may have contributed to the Brexit and Trump election victories. In addition, cognitive $C Q$ informs the appropriate adjustment of both verbal and non-verbal behaviours during cross-cultural encounters (behavioural $C Q$ ). These results provide some evidence of the need for accounting academics to increase their knowledge of cultural norms, values, practices and conventions associated with different societies, together with their differences, to increase their level of cognitive $C Q$.

In terms of the level of $C Q$ and its components, Table 3 provides comparative data in rank order for the total $\mathrm{CQ}$ mean scores, in addition to $\mathrm{CQ}$ component mean scores, for cohorts from 14 studies. It also provides the number of observations for each prior study to facilitate its use as a comparison tool. The studies listed in Table 3 encompass a wide variety of cohorts, including international school leaders working in 90 countries (Keung \& Rockinson-Szapkiw, 2013), expatriates living and working in various countries (H. K. Moon et al., 2012; Ramalu et al., 2010; Wu \& Ang, 2011), leaders and members of multicultural teams (Flaherty, 2008; Groves \& Feyerherm, 2011), working professionals who are also part-time MBA students (Wood \& St. Peters, 2013) and Turkish military personnel (Sahin et al., 2014). The studies were selected on the basis that they had utilised the full 20-item CQS (Ang et al., 2007) as the survey instrument, and had published the mean and standard deviations for each of the four $C Q$ components, rather than for total $C Q$ only. Comparing the $C Q$ scores for accounting academics to those obtained by the respondents in Table 3 , accounting academics rank seventh (prior to rounding of total CQ mean) of the 15 studies with respect to total $C Q$. When ranked according to each of the four components of $C Q$, they are ranked sixth with respect to metacognitive $C Q$, seventh with respect to cognitive $C Q$ and motivational $C Q$, and fifth with respect to behavioural $C Q$. In all studies, including this study, the cognitive component recorded the lowest mean. As noted earlier, the respondents in this study rated themselves highly on the metacognitive $C Q$ component, only marginally ahead of motivational $C Q$. 
Respondents in only three other studies have done likewise (Chen et al., 2011; Lin et al., 2012; H. K. Moon et al., 2012). In all other studies, with one exception (H. K. Moon, 2010), motivational $C Q$ recorded the highest mean.

\section{[Insert Table 3 about here]}

Relative to respondents in previous studies, it appears that accounting academics possess levels of $C Q$ that sit at the mid-point to those in a sample of $C Q$ studies encompassing a diverse range of cohorts (see Table 3). Moreover, accounting academics have lower levels of $C Q$ than those reported in prior studies involving other professional cohorts. Their $C Q$ levels exceed only those of research subjects who are part-time students, employed in the military, and unskilled workers and students. These findings are of serious concern if one takes the view that possession of cross-cultural capabilities is an essential requirement for not only effective teaching in today's multicultural university environment, but also for avoiding the types of perspectives that result in biases against ethnic groups, and immigrants in general. It is acknowledged that this comparison should be interpreted with caution as the other studies employed diverse approaches to data collection and the composition and characteristics of the samples may be quite different ${ }^{3}$. Byrne, Shavelson, and Muthén (1989) argue that such comparisons are only meaningful when the psychometric equivalence across the studies can be established. Nonetheless, the results from prior studies provide an interesting, albeit limited, point of comparison to the results obtained in our study.

\subsection{Antecedents of CQ}

Following reliability and validity testing, one-way ANOVA tests were conducted to determine significance between group means. An analysis of variance showed that the effect of the following independent variables were significant on Total $C Q$; LangSpoken, $(F(1,251)=$ 4.930, $p=.027) ;$ TaughtOffshore(Asia), $(F(1,251)=8.184, p=.005)$; and OverseasRes, $(F(1,251)=12.955, p=.000)$. There were no statistically significant differences for the independent variables CityUni, Gender, Age and TeachExp on Total CQ.

OLS regression was then employed to examine the associations between the various $C Q$ scores employed in the study and various demographic and other factors for Australian accounting academics. Accordingly, independent variables were estimated in the following model:

\footnotetext{
${ }^{3}$ It is acknowledged that the CQS is a self-reporting instrument. This may result in different groups having a tendency to mark themselves more harshly than other groups on some or all of the questions due to their professional proclivities.
} 


$$
\begin{aligned}
& \mathrm{CQ}=b_{0}+b_{1}{ }^{\star} \text { CityUni }+b_{2}{ }^{*} \text { Gender }+b_{3}{ }^{*} \text { Age }+b_{4}{ }^{*} \text { TeachExp }+b_{5}{ }^{*} \text { LangSpoken }+ \\
& b_{6}{ }^{*} \text { TaughtOffshore(Asia) }+b_{7}{ }^{\star} \text { TaughtOffshore }(\text { Anglo })+b_{8}{ }^{*} \text { OverseasRes }+e
\end{aligned}
$$

The independent variables are defined as follows:

$\begin{array}{ll}\text { CityUni } & \begin{array}{l}\text { employed at university located in State or Territory capital city }=1 ; 0= \\ \text { otherwise } \\ \text { female }=1 ; \text { male }=0\end{array} \\ \begin{array}{l}\text { Gender } \\ \text { Age }\end{array} & \begin{array}{l}\text { more than } 15 \text { years tertiary teaching experience }=1 ; 0=\text { otherwise } \\ \text { TeachExp }\end{array} \\ \begin{array}{l}\text { LangSpoken } \\ \text { taught offshore in Singapore, Hong Kong, Malaysia or mainland China }=1 ; \\ \text { TaughtOffshore(Asia) }\end{array} & \begin{array}{l}0=\text { otherwise } \\ \text { taught offshore in UK, US, Canada, and New Zealand }=1,0 \text { otherwise } \\ \text { TaughtOffshore(Anglo) } \\ \text { OverseasRes }\end{array} \\ & \text { no }=045\end{array}$

In the model above, the $C Q$ variable captures the Total $C Q$ of each respondent in the sample as derived from each of the four different interrelated capabilities (metacognitive, cognitive, motivational, and behavioural). Following previous research on CQ (Groves \& Feyerherm, 2011), five separate models were run: with Total $C Q$, Metacognitive $C Q$, Cognitive $C Q$, Motivational $C Q$ and Behavioural $C Q$ as dependent variables. The models test how proxies for higher exposure to different cultures are associated with $C Q$.

Age and TeachExp were expected to be positive due to older participants and participants with a greater amount of teaching experience potentially being exposed to a greater number of culturally diverse opportunities, thereby leading to an increase in $C Q$. Based on the findings of Harrison (2012), LangSpoken was expected to be positive. No prediction was made regarding the expected direction for CityUni and Gender.

The TaughtOffshore(Asia), TaughtOffshore(Anglo) and OverseasRes variables capture the international experience of the respondents and were expected to be positive for total CQ and all four components of $\mathrm{CQ}$, following the findings of previous studies examining international

\footnotetext{
${ }^{4}$ It is recognised that overseas residency can be measured in different ways e.g. as a dichotomous variable of whether or not they resided overseas for greater than a set period, or alternatively listing the number and length of experiences (Takeuchi, Tesluk, Yun, \& Lepak, 2005). It is acknowledged that due to insufficient data being provided by all respondents about the total number of years of overseas residency, a limitation of this study is that the OverseasRes is captured by a dichotomous variable. The particular approach adopted may have an impact on analysis.

${ }^{5}$ It should be noted that the overseas residency measure captures those who have lived abroad rather than born abroad. If respondents provided a 'yes' response to the question 'Have you resided in a country, other than Australia, for a continuous period exceeding 12 months?', they were then asked to specify in which country/countries, the length of their residency and the actual years they were there. Based on the response to the question about their age, it was possible to confirm for the majority of the respondents that the international residency period did not occur in their country of origin, or if it did, that there was also a further period/s of international residency in accordance with the definition specified in this study.
} 
experience (Crowne, 2008; Shannon \& Begley, 2008; Tay et al., 2008). In order to examine the effect of cultural distance (Hofstede et al., 2010), the TaughtOffshore test variable is separately coded according to transnational teaching in Southeast Asia, (TaughtOffshore(Asia), specifically Singapore, Hong Kong, Malaysia, and mainland China), in Anglophone countries (TaughtOffshore(Anglo), specifically UK, US, Canada and New Zealand) and in Europe (TaughtOffshore(Europe)). TaughtOffshore(Asia) and TaughtOffshore(Anglo) are the variables used in the above model and TaughtOffshore(Europe) is the default group. As a number of independent variables were estimated in our model to further understand the antecedents of $C Q$, coding the TaughtOffshore test variable according to location was selected as the best approach to examine cultural distance based on the data provided by respondents.

Table 4 reports correlations between total $C Q$, in addition to each of the four CQ components, and independent variables. As shown in Table 4, no major collinearity exists between the variables $^{6}$. To assess the possibility of collinearity problems, VIF scores were also calculated and found to be within acceptable parameters (Hair et al., 2010).

[Insert Table 4 about here]

Table 5 displays the results of the regression analyses ${ }^{7}$. All five models are highly significant. While the adjusted $R^{2}$ s are not high (9.5\% for the Total CQ model), they are consistent with those obtained in other studies of antecedents of CQ (Shannon \& Begley, 2008; Tay et al., 2008; Van Dyne et al., 2008) and reflect the complexity of modelling a multi-faceted attribute such as CQ. CQ comprises four distinct but interrelated capabilities and therefore identifying all variables that might fully explain its incidence is impracticable.

[Insert Table 5 about here]

\subsection{Empirical results and discussion}

An examination of Table 5 indicates four of the variables, namely Age, TeachExp, TaughtOffshore(Asia) and Overseas Res, are significant in the Total CQ model at a minimum of $5 \%$ level (all significance levels are reported as one-tailed). Moreover, each of the variables,

\footnotetext{
${ }^{6}$ Initial correlation testing indicated some collinearity between AccPos and TeachExp, and EngFirstLang and LangSpoken. The number of years of tertiary teaching experience (TeachExp) was considered a more comprehensive measure of experience than AccPos; accordingly, AccPos was removed during regression analysis. In order to test the findings of Tarique and Takeuchi (2008) and Harrison (2012), EngFirstLang was removed during analysis in favour of LangSpoken. Removal of these two variables did not significantly impact on the regression results.

${ }^{7}$ Measures of kurtosis and skewness were calculated to test for violations of the assumptions of regression (Field, 2013). In addition, scatter plots of the regression standardised residual against the regression standardised predicted value were undertaken. Analysis of these tests and plots indicate that the models and variables are not likely to be miss-specified due to problems with linearity and homoscedasticity.
} 
with the exception of TeachExp, is significant in the direction expected. The Cognitive CQ and Behavioural CQ models have six significant independent variables, the Metacognitive $C Q$ and Motivational CQ models have four significant independent variables. TaughtOffshore(Asia) and OverseasRes is significant in all five models at a minimum of $5 \%$ level.

Consistent with the findings from previous studies (Engle \& Crowne, 2014; Harrison, 2012; MacNab \& Worthley, 2012), the Gender independent variable is insignificant in the Total CQ model. However, the Gender variable was found to be positive and statistically significant at the $10 \%$ level in the Behavioural CQ model, suggesting that female accounting academics are more capable of appropriately adapting their behaviour in different cultural settings. It should be noted that in previous studies most respondents were male and were largely employed in the manufacturing and technology sectors (Flaherty, 2008; Ramalu et al., 2010; H. K. Moon et al., 2012), in addition to the military (Sahin et al., 2014). In contrast, the cohort examined in this study was employed in the education sector, one in which relationships with, and interaction between, people are arguably of greater importance. Studies have found that expatriates who have the ability to communicate well with local partners or develop relationships with locals perform better than those who cannot (Lee \& Sukoco, 2008). Therefore, it is possible that the context of the present study, academia, which is very much a people-orientated industry, has had an influence on the findings in the Behavioural CQ model.

Age is positive and significant in all models $(p<0.05$ for Total $C Q$, Metacognitive $C Q$, Cognitive $C Q$ and Motivational $C Q, p<0.10$ for Behavioural $C Q$ ), indicating a natural barrier in younger people accumulating $C Q$. This could be because younger academics have had fewer opportunities to broaden their cultural experiences. Furthermore, while respondents in the lower age groups were more likely to speak more than one language, they did not have the same levels of teaching experience, either domestically or transnationally, as their older counterparts. Of the 84 respondents aged less than 45 , only 9 respondents (11\%) had more than 15 years teaching experience, and 30 respondents (36\%) had taught transnationally in Southeast Asia. Among their counterparts aged 45 years or older, $114(68 \%)$ respondents had more than 15 years teaching experience, and 108 (64\%) had taught transnationally in Southeast Asia. A possible explanation for the lower levels of transnational teaching experience amongst younger academics is that they may be employed at universities who were previously engaged in transnational education, but have now withdrawn for strategic reasons or non-viability reasons (Clayton \& Ziguras, 2011).

The TeachExp variable is negative and significant in all models except the Behavioural CQ model $(p<0.001$ for Motivational $C Q, p<0.05$ for Total $C Q$ and Cognitive $C Q$ and, $p<0.10$ for 
Metacognitive $\mathrm{CQ}$ ), indicating that academics with 15 years or less tertiary teaching experience $^{8}$ accumulate higher CQ levels. The expected direction for TeachExp was positive; one possible explanation for this unexpected result is that many accounting academics employed at Australian universities in recent years have originated from overseas (Cappelletto, 2010; O'Connell et al., 2015). As the results in this study show, those with lower levels of teaching experience are more likely to have resided overseas and speak more than one language, thereby providing a potential boost in their $C Q$ levels. This interesting finding suggests that universities should identify academics who have limited international experience and/or residence and provide them with professional development in the $C Q$ area. It also demonstrates the importance of universities specifying cross-cultural capabilities in selection criteria for new academics.

The LangSpoken variable is positive in all models except Motivational CQ, and significant at the $5 \%$ level only in the Cognitive CQ model. This indicates that academics who speak one or more languages fluently, apart from English, have higher levels of that capability. The results for the LangSpoken variable are consistent with Harrison (2012); in learning another language, a parallel learning of its culture, along with its similarities and differences, normally tends to occur. A possible explanation for the negative association between LangSpoken and motivational $C Q$ is academics that speak one or more languages, while exhibiting higher levels of metacognitive $C Q$, cognitive $C Q$ and behavioural $C Q$, may not be as motivated in diverse cultural contexts as their counterparts who do not speak another language, due to potentially greater familiarity in situations characterised by cultural diversity.

\subsection{Considerations of international experience and CQ}

The TaughtOffshore(Asia) variable, which measures whether the respondents have previously taught in Southeast Asia (Singapore, Hong Kong, Malaysia or mainland China), is positive and significant across all models at a minimum of $5 \%$ level. The findings regarding TaughtOffshore(Asia) indicate that those who have taught transnationally in Southeast Asia have higher levels of $C Q$. Notwithstanding the many cultures that exist in Australian domestic classrooms (Gribble \& Ziguras, 2003), the experience of teaching transnationally in Southeast Asia is found to be significant and positively associated with the $C Q$ levels of Australian accounting academics across all four components. Previous studies examining work-related international experience have revealed significant relationships between international experience and $C Q$, but the findings have not been consistent across the four components (Crowne, 2008; Shannon \& Begley, 2008; Tay et al., 2008). It is possible that - due to Australia's geographical isolation - some of the respondents in this study have not or rarely

\footnotetext{
${ }^{8}$ The holding of a formal teaching qualification was also tested for and found not to be significant.
} 
travelled internationally, particularly beyond Anglophone countries. Therefore, an international teaching experience in Southeast Asia is more likely to have a marked influence on their $\mathrm{CQ}$ levels than on respondents from smaller countries bordering multiple nations consisting of diverse cultures. Transnational teaching allows Australian accounting academics to interact with students and other locals in the host country; this research suggests that these experiences can produce a meaningful increase in $C Q$. The empirical findings of this study indicate that even brief work-related international experiences can have a positive effect on $\mathrm{CQ}$, which is in contrast to $\mathrm{H}$. K. Moon et al. (2012). It appears that short-term transnational teaching experiences allow sufficiently meaningful interaction and engagement with the local culture (Osland \& Osland, 2006), particularly through students, such that an enhancement in CQ levels occurs.

Furthermore, our study responds to calls from Lee and Sukoco (2010) and Engle and Crowne (2014) to explore international experience in the area of cultural distance. According to both the Global Leadership and Organizational Behavior Effectiveness (GLOBE) Model (House et al., 2004) and Hofstede et al. (2010), there is greater cultural distance between Australia and Southeast Asia than there is between Australia and Anglophone countries, or between Australia and Europe. Indeed, Australia and Southeast Asia are approaching 'opposite poles' in terms of cultural distance (Hofstede et al., 2010, p.92). The regression models in our study using the separately coded TaughtOffshore variable yielded quite different results, with the TaughtOffshore variable coded for teaching in Southeast Asia consistently providing positive statistically significant relationships with total $C Q$ and all four $C Q$ components. In contrast, results in the regression models for teaching in Anglophone countries, TaughtOffshore(Anglo), is only significant in the Cognitive $C Q(p<0.05)$ and Behavioural $C Q(p<0.10)$ models. Unreported results in the regression models for teaching in Europe, TaughtOffshore(Europe), were not significant. These findings provide new understanding of the impact of cultural distance on $C Q$. They suggest that individuals undertaking an international experience where the international host environment is markedly different to the home environment have higher CQ levels.

This finding also builds on the management literature relating to the influence of international work experiences (see, for example, Dragoni et al., 2014; McCall \& Hollenbeck, 2002). For example, Dragoni et al. (2014) studied how organisations can develop leaders who think strategically by investigating the impact of leaders' global work experiences. Importantly, and of relevance to our finding above, they found that some leaders gain more from global work experiences than others. Specifically, those exposed to a more culturally distant country seem to benefit the most: 
When individuals are exposed to a culture that is very different from their own (i.e., high in cultural distance), their existing schemas are challenged. When encountering cultural distance, individuals are challenged by salient contrasts and counterpoints to their current view of the institutional environment, particularly their implicit assumptions about people, their habits, and motivations (Dragoni et al., 2014, p. 869).

They also find that not only do these managers make better strategic decisions, they are better able to glean lessons from key international experiences, and thereby realise higher levels of effectiveness, by broadening their worldviews, attitudes, and behaviour. In our study, international experiences in culturally distant countries appear to have a significant influence on academics' overall $C Q$ levels.

The OverseasRes variable is positive and significant in all models at a minimum of $5 \%$ level, indicating those who have resided overseas for a continuous period greater than twelve months have higher levels of CQ. Overseas residency, defined in our study as living outside Australia for a continuous period greater than twelve months, captures the impact of a deep international experience due to prolonged exposure to the host nation's culture. The regression results suggest that residing overseas affords opportunities to experience immersion in the local culture by moving beyond the hotel room, tourist sites and restaurants serving familiar food to, for example, shopping for fresh produce in local markets and spending leisure time with locals. Short-term visits generally do not offer the same opportunities. This result is in contrast to Crowne (2008), who found that 'currently living outside an individual's country of citizenship' (p. 395) negatively impacted behavioural CQ. However, the absence of a time period attached to Crowne's measure could mean participants were living overseas for a few days or several years at the point of responding to the survey. As a result, respondents could have very different levels of overseas experience and give potentially markedly different responses, thereby leading to an inconsistency in results. This study has therefore defined and examined a new measure to capture the impact of long-term international experience on $\mathrm{CQ}$. However, this result should be interpreted with some caution, as it is possible that it is the characteristics of individuals themselves who choose to participate in international experiences, in addition to the experience itself, which is responsible for the higher CQ levels exhibited by this cohort.

Further analysis is undertaken to examine the effect of cultural distance by separately coding the variable OverseasRes according to overseas residency in Southeast Asia (specifically Singapore, Hong Kong, Malaysia, and mainland China), in Anglophone countries (specifically UK, US, Canada and New Zealand), and in Europe, with no statistically significant results being obtained. A possible explanation is that the main results are confounded due to the majority of the respondents who had resided in a country other than Australia for a period of 
longer than 12 months, had done so in various countries spanning a number of continents and therefore it was not possible to identify the particular host environment that had significantly contributed to the development of their $\mathrm{CQ}$. It is possible that prolonged exposure to a variety of host cultures, including those both close and distant to the individual's home culture, collectively contribute to the development of an individual's $C Q$ in a meaningful way. From a theory perspective, it is therefore difficult to geographically isolate the precise impact of cultural distance on overseas residency and its relationship to $C Q$, given individuals diverse and often multiple long-term international experiences.

\subsection{0ther sensitivity analyses}

Given the exploratory nature of our study, other variables are added to the main model to test the robustness of results. For example, based on prior studies (Crowne, 2008, 2013), the number of countries in which accounting academics had previously taught could potentially be a factor that influences their $C Q$ levels. We have, therefore, included a variable that captures the diversity in the overseas teaching that respondents have had, and rerun the main models of the study. The new dummy variable is defined as one for those academics who have taught in more than five different countries, and zero otherwise. The results have showed that those academics who taught in more than five different countries possess significantly higher $C Q$ levels, although the relationship is only weakly significant ( $p=.055$, one-tail).

Other potential factors that potentially could influence the CQ levels of accounting academics are the number of times that each academic has taught overseas, the university position held by each academic, and whether accounting academics possess a formal teaching qualification. Separate variables are created for each of these potential factors. When each of these variables were included in the main regression model (either alone or in various combinations), all have been insignificant in determining the $C Q$ levels of accounting academics. Furthermore, after inclusion of the additional control variables the relationships reported in each of the five models in Table 5 did not alter in terms of significance or direction. Consequently, the main results reported in Table 5 remain unchanged.

To further understand the potential impact of international experience on total $C Q$ and its four components, additional models were run controlling for total $C Q$ on each of the four models of $\mathrm{CQ}$ components. As expected, total $C Q$ was positive and highly significant in all models. Most of the other variables in these analyses remain qualitatively the same as reported in Table 5, with some minor variations.

When we include three out of the four individual $C Q$ components in the Total $C Q$ model, the results become somewhat unstable compared to the results reported in Table 5 , mainly due 
to the high multicollinearity between Total $C Q$ and its $C Q$ components. Equally, we get disturbed results when we rerun the Total $C Q$ model and replace the individual $C Q$ components with their underlying constructs, i.e., using the raw questions in the model as control variables.

\section{Conclusion}

In a contemporary environment characterised by the rise of xenophobia and anti-immigration stances by some elements of society, as epitomised in the Brexit vote and election of Donald Trump in the US amongst others, the procession of strong levels of CQ is critical. None more so than for academics given their significant interaction with, and influence over, students who will become our future leaders. Students move into influential roles upon graduation and it is the value of their education that equips them to (hopefully) reject ill-informed and prejudiced views encountered in their professional and broader lives. Academics, and universities in general, should be preparing them for a successful and fulfilled life that includes positive contributions to the communities in which they live and work. Furthermore, accounting academics are required to operate effectively in multicultural teaching and research teams and manage the culturally diverse classrooms that now exist within the contemporary internationalised university (Harrison, 2012; Tange \& Jensen, 2012). Despite its critical importance, little understanding exists regarding the capacity or preparedness of academics to fulfil these requirements. In order to address this lacuna in understanding, this study examined the cross-cultural capabilities of accounting academics using $C Q$ as a theoretical lens. Our study has identified that the $C Q$ levels of accounting academics are below average relative to other professional groups, and in particular, their cognitive $C Q$ and motivational $C Q$. In examining the antecedents of $C Q$, our study found international experience (as captured by teaching in Southeast Asia and overseas residency) to be significant and positively associated with higher levels of total $C Q$ and each of the components of $C Q$. In particular, this study provides evidence that individuals undertaking an international experience in a host environment culturally distant to their home environment are more likely to have higher $C Q$ levels. Other variables found to be significant are age, which is positively associated with $C Q$ and significant in all models, and teaching experience which is negatively associated with $C Q$ and significant in all models except behavioural $C Q$. The number of languages spoken is positive in all models except motivational $C Q$, and significant in the cognitive $C Q$ model. Gender is found to be positive and statistically significant in the behavioural CQ model, indicating female accounting academics are more capable of adjusting their behaviour in culturally diverse situations. 
Our study makes two important contributions to $C Q$ scholarship. First, this study has further extended knowledge of the antecedents of $C Q$ in the context of international experience by examining the potential impact of short-term overseas teaching experiences. Furthermore, it has examined new measures capturing the depth and breadth of international experience; that of long-term overseas residency and cultural distance. Previous measures used to capture international experience were limited to the number of countries visited and crude proxies for the number of days associated with short-term international trips. Our study found that international experience (particularly in a country culturally distant from the academic's home country) and long-term international experiences have a significant impact on $C Q$ levels. Cultural distance has not previously been examined in $C Q$ scholarship and therefore is a possible explanation for the differing results obtained in previous studies examining international experience and CQ. This study also confirms the findings from previous studies with respect to the impact of language ability on cognitive $C Q$ levels. The impact of gender on behavioural $C Q$ is a new finding.

Second, this study has brought CQ to the attention of the discipline of accounting which, in either the professional or educational contexts, has not previously been examined. The accounting profession needs to embrace cultural diversity, not only for commercial reasons, but also from a public-interest perspective as outlined earlier (see, for example ICAEW, 2015b). The documented existence of ethnicity-based discrimination within the profession should no longer be tolerated. In developing teaching excellence, the accounting academe needs to consider how it will embrace, engage and retain the large international student contingent, while simultaneously integrating them with the domestic cohort. This study provides a possible avenue for dealing with these significant and complex issues. Understanding the factors that lead to higher levels of $C Q$ is of significant relevance to the accounting profession, universities, and academics as individuals and team members functioning in environments with a level of cultural diversity rarely found elsewhere.

Our study also contributes to the management literature in the area of international work experience (see, for example, Dragoni et al., 2014; McCall \& Hollenbeck, 2002). Specifically, the finding of the impact of exposure to a more culturally distant country on CQ complements and extends the work of Dragoni et al. (2014) on managers' international work experiences.

This study possesses five limitations. First, while the CQS is the most popular method of assessing cross-cultural competency (Gelfand et al., 2008) and has been shown to be reliable across diverse settings and cohorts (Ang et al., 2007), it is a self-assessed questionnaire and thus carries with it all the usual limitations associated with such methods. Individuals might 
provide responses perceived to be socially desirable (Geiger \& O'Connell, 2000); respondents can overrate their own skills and abilities (Dunning, Heath, \& Suls, 2004), particularly those with low competence (Kruger \& Dunning, 1999), as they are not always able to identify skills that they do not possess (Ehrlinger, Johnson, Banner, Dunning, \& Kruger, 2008). However in developing the CQS, Van Dyne et al. (2008) found a positive and significant relationship between overall self-rated and peer-rated CQ. Furthermore, Mabe and West (1982) found that long-term and older employees respond more accurately when completing intelligence questionnaires and have generally completed numerous surveys. In this study, almost half of the respondents had 15 or more years of teaching experience and $67 \%$ were aged 45 years or older. In addition, academics as a cohort are well accustomed to completing questionnaires and understand the importance of reporting accurate data.

Second, the generalisability of findings to academics in other nations must be considered. While this study has examined accounting academics in one western country, the findings are relevant to other nations and disciplines. The Australian higher education environment is not dissimilar to that of other countries in that it is a major destination country for international students and has a well-developed educational and economic system. Furthermore, accounting is not the only discipline attracting large numbers of international students.

Third, there is a possibility of reverse causality whereby those individuals with higher CQ seek out more international experiences. However, we believe this possibility to be limited in that our study uses a large sample, and the choice to work overseas is not always at the discretion of academics. Accordingly, further research could be undertaken that controls for the level of employee choice in overseas assignments or adopts a longitudinal approach.

Fourth, our sample while relatively large, did exclude adjunct professors, emeritus professors, research fellows, doctoral students and sessional (part-time) staff. This may reduce the generalisability of the study to the entire population of university teaching staff.

Fifth, respondents in this study were not asked for their country of birth. This leaves open the possibility that the effects of overseas residency may vary according to respondents' country of origin. For example, the overseas residency of an Australian in the U.S. may provide a different intercultural experience than the overseas residency experience of a mainland Chinese in the U.S. However, it should be noted that they were asked about whether or not English was their first language and the number of languages spoken other than English. As discussed in Section 3.1 of the paper. Baskerville, Wynn-Williams, Evans, and Gillett (2014) 
highlight that the use of 'first language' is a justifiable proxy for ethnicity. Future research could be undertaken to explore the potential impact of country of birth.

Turning to avenues for future research, additional research into the $C Q$ levels of accounting professionals and what might impact on these is needed given the rise of shared services, offshoring and general globalisation of the profession. Furthermore, longitudinal studies into the development of individuals' $C Q$ levels over time would further elucidate understanding of the factors that drive its improvement. Different measures of international experience could be included in future studies to increase understanding of its complex impact. Future research could be undertaken to expand on the finding that overseas residency is positively associated with $C Q$, such as for example, examining the potential impact of length of overseas residency on $C Q$ (is there a minimum length?), whether the benefits of overseas residency plateau over time, and whether specific experiences such as study or travel during the residency affect each of the $C Q$ components differentially. Elements of overseas residency may contribute differentially to the development of the four $C Q$ components. For example, the effects of the presence of family and/or partner during the overseas residency, the partner's country of origin, promotion opportunities arising from the overseas residency experience, or the extent of international travel during the overseas residency would be interesting avenues to explore in this regard. Future research opportunities exist to build on the finding from this study that international teaching trips are positively related to $C Q$ only when those teaching assignments occurred in culturally more distant (i.e., Southeast Asian) countries. The current study, and Engle \& Nash (2016) in examining international non-work-experiences, consider cultural distance as a dichotomous variable. Further research could examine the potential impact on $\mathrm{CQ}$ development of differing levels of cultural distance. Other interesting extensions may be to examine the effects of diverse measures of cultural distance such as psychological cultural distance (Demes \& Geeraert, 2014), cultural friction (Shenkar, 2012), or asymmetric cultural distance effects (Zhang \& Oczkowski, 2016). While international experience has been found to be positively related to $C Q$, little is known about an individual's propensity to learn or the processes through which these experiences are translated into $C Q$. Research surrounding an individual's ability to internalise the international experience, or the existence of certain personality traits is required. It is possible that the existence and nature of pre-departure training and supportive mechanisms (both formal and informal) may have an influence on translating the international experience into higher levels of $\mathrm{CQ}$. Further studies employing qualitative methods, such as interviews and observation, would assist in elucidating these areas. Our findings also highlight one evolving skill requirement of academics; that of $C Q$. Building on the work of Spence and Carter (2014) and Carter and Spence (2014), scope exists for researchers to utilise Bourdieu's (2012) notion of different capitals and cultural reproduction 
to examine the changing skill sets for academics to operate effectively. Following on from the preceding paragraph, future research could also examine classroom cultural diversity using academics involved in university teaching on a less than full-time basis. Finally, future studies examining academics from a range of countries and disciplines would provide a more comprehensive picture of $C Q$ levels within the global higher education sector.

\section{Acknowledgements}

Acknowledgement is made to the following people for their helpful suggestions: Lee Parker, Rob Gray, Christine Helliar, Dennis Taylor, Prem Chhetri, Jacqueline Birt, and the two anonymous reviewers for this journal. The authors would also like to thank participants at the following conferences for their helpful comments: Accounting and Finance Association of Australia and New Zealand (AFAANZ) Annual Conference, the European Accounting Association (EAA) Annual Congress, the British Accounting and Finance Association (BAFA) Accounting Education Special Interest Group and the RMIT Accounting Educators' Conference. 


\section{REFERENCES}

Abraham, A. (2006). The need for the integration of emotional intelligence skills in business education. The Business Renaissance Quarterly, 1(3), 65-80. Accessed August 2, 2018.

AFAANZ. (2012). Presidents' message. AFAANZ Newsletter, September. Available on the internet at http://www.afaanz.org/images/stories/pdfs/newsletters/newsletter september_12.pdf Accessed October 25, 2014.

AFAANZ. (2014). Presidents' message. AFAANZ Newsletter, September. Available on the internet at http://www.afaanz.org/images/stories/pdfs/newsletters/Newsletter_September_14.pdf Accessed October 25, 2014.

AICPA. (2016). Advancing cultural intelligence in the accounting profession. Available on the internet at http://www.aicpa.org/PUBLICATIONS/NEWSLETTERS/CPALETTERDAILY/Pages/d efault.aspx Accessed April 20, 2016.

Alon, I., \& Higgins, J. M. (2005). Global leadership success through emotional and cultural intelligences. Business Horizons, 48(6), 501-512.

Altbach, P. G., \& de Wit, H. (2017). Revolutions ahead in international student mobility. University World News, April 7, 2017. Available on the internet at http://www.universityworldnews.com/article.php?story $=2017040412022639$ Accessed August 2, 2018.

Ang, S., \& Van Dyne, L. (2008). Conceptualization of cultural intelligence: Definition, distinctiveness, and nomological network. In S. Ang \& L. Van Dyne (Eds.), Handbook of cultural intelligence: Theory, measurement, and applications (pp. 3-15). New York: M.E. Sharpe.

Ang, S., Van Dyne, L., \& Koh, C. (2006). Personality correlates of the four-factor model of cultural intelligence. Group \& Organization Management, 31(1), 100-123.

Ang, S., Van Dyne, L., Koh, C., Ng, K.-Y., Templer, K. J., Tay, C., \& Chandrasekar, N. A. (2007). Cultural Intelligence: Its measurement and effects on cultural judgement and decision making, cultural adaptation and task performance. Management and Organization Review, 3(3), 335-371.

Ang, S., Van Dyne, L., \& Tan, M. L. (2011). Cultural intelligence. In R. J. Sternberg \& S. B. Kaufman (Eds.), Cambridge handbook of intelligence (pp. 582-602). Cambridge, UK: Cambridge University Press.

Australian Government. (2016). The global context of tertiary student mobility. Department of Education and Training, Research Snapshot, December 2016. Available on the internet at https://internationaleducation.gov.au/research/ResearchSnapshots/Documents/Global\%20context\%20of\%20tertiary\%20student $\% 20$ mobility.pdf

Baskerville, R. F., Jacobs, K., Joannides de Lautour, V., \& Sissons, J. (2016). Ethnicity as inclusion and exclusion: Drawing on concept and practice in accounting research. Accounting, Auditing \& Accountability Journal, 29(8), 1262-1269.

Baskerville, R. F., Wynn-Williams, K., Evans, E., \& Gillett, S. (2014). Researching ethnicity in the Pacific region. Pacific Accounting Review, 26(3), 302-323. 
Bay, D., \& McKeage, K. (2006). Emotional intelligence in undergraduate accounting students: Preliminary assessment. Accounting Education, 15(4), 439-454.

Bhagat, R. S., \& Prien, K. O. (1996). Cross-cultural training in organizational contexts. In D. Landis \& R. S. Bhagat (Eds.), Handbook of intercultural training (pp. 216-230). Thousand Oaks, CA: Sage.

BIS. (2013). International Education - Global Growth and Prosperity: An Accompanying Analytical Narrative. Available on the internet at https://www.gov.uk/government/uploads/system/uploads/attachment_data/file/340601/bis -13-1082-international-education-accompanying-analytical-narrative-revised.pdf Accessed August 2, 2018.

Blasco, M., Feldt, L. E., \& Jakobsen, M. (2012). If only cultural chameleons could fly too: A critical discussion of the concept of cultural intelligence. International Journal of Cross Cultural Management, 12(2), 229-245.

Bourdieu, P. (2012). La fabrique des débats publics. Le Monde diplomatique, Janvier.

Bucker, J., Furrer, O., \& Lin, Y. (2015). Measuring cultural intelligence (CQ): A new test of the CQ scale. International Journal of Cross Cultural Management, 15(3), 259-284.

Byrne, B. M., Shavelson, R. J., \& Muthén, B. (1989). Testing for the equivalence of factor covariance and mean structures: The issue of partial measurement invariance. Psychological Bulletin, 105, 456-466. Psychological Bulletin, 105(3), 456-466.

Cappelletto, G. (2010). Challenges facing accounting education in Australia: A joint accounting bodies and AFAANZ commissioned report. Available on the internet at http://www.afaanz.org/images/stories/pdfs/general pdf/challeges $\% 20$ facing $\% 20$ accounti ng\%20education\%20report\%20-\%202010.pdf Accessed March 14, 2013.

Carter, C., \& Spence, C. (2014). Being a successful professional: An exploration of who makes partner in the Big 4. Contemporary Accounting Research, 31(4), 949-981.

CGMA. (2016). The case for cultural intelligence. Available on the internet at http://www.cgma.org/magazine/features/pages/cultural-intelligence.aspx Accessed October 6, 2016.

Chen, A. S.-Y., Lin, Y.-C., \& Sawangpattanakul, A. (2011). The relationship between cultural intelligence and performance with the mediating effect of culture shock: A case from Philippine laborers in Taiwan. International Journal of Intercultural Relations, 35(2), 246-258.

Chia, Y. M. (2005). Job offers of multi-national accounting firms: The effects of emotional intelligence, extra-curricular activities, and academic performance. Accounting Education, 14(1), 75-93.

Clayton, D., \& Ziguras, C. (2011). Transnational Education: Delivering quality programs offshore. In D. Davis \& B. Mackintosh (Eds.), Making a difference: Australian international education (pp. 302-330). Sydney: NewSouth Publishing.

Cook, G. L., Bay, D., Visser, B., Myburgh, J. E., \& Njoroge, J. (2011). Emotional intelligence: The role of accounting education and work experience. Issues in Accounting Education, 26(2), 267-286.

Cooper, B. J., \& Adams, K. (1997). The export of accountancy education to Malaysia and Singapore: An Australian experience. Asian Review of Accounting, 5(2), 109-123.

CPA Australia. (2014). Mining and energy accounting forum 2014. Available on the internet at http://www.cpaaustralia.com.au/cpd/Mining-and-energy-accounting-forum-2014poster.pdf Accessed March 16, 2014.

Crowne, K. A. (2008). What leads to cultural intelligence? Business Horizons, 51(5), 391-399. 
Crowne, K. A. (2013). Cultural exposure, emotional intelligence, and cultural intelligence: An exploratory study. International Journal of Cross Cultural Management, 13(1), 5-22.

Daff, L., de Lange, P., \& Jackling, B. (2012). A comparison of generic skills and emotional intelligence in accounting education. Issues in Accounting Education, 27(3), 627-645.

Deloitte. (2015). Fast forward: Leading in a brave new world of diversity. Available on the internet at https://www2.deloitte.com/content/dam/Deloitte/au/Documents/humancapital/deloitte-au-hc-trends-forward-diversity-290515.pdf Accessed August 2, 2018.

Demes, K. A. \& Geeraert, N. (2014). Measures matter: Scales for adaptation, cultural distance, and acculturation orientation revisited. Journal of Cross-Cultural Psychology, 45(1): 91109.

Dragoni, L., Tesluk, P. E., VanKatwyk, P., In-Sue, O., Moore, O. A., \& Hazucha, J. (2014). Developing leaders' strategic thinking through global work experience: The moderating role of cultural distance. Journal of Applied Psychology, 99(5), 867-882.

Dunning, D., Heath, C., \& Suls, J. M. (2004). Flawed self-assessment: Implications for health, education, and the workplace. Psychological Science in the Public Interest, 5(3), 69-106.

Earley, P. C., \& Ang, S. (2003). Cultural intelligence: Individual interactions across cultures. Palo Alto, CA: Stanford University Press.

Earley, P. C., Ang, S., \& Tan, J. (2006). CQ: Developing cultural intelligence at work. Stanford: Stanford University Press.

Ehrlinger, J., Johnson, K., Banner, M., Dunning, D., \& Kruger, J. (2008). Why the unskilled are unaware: Further explorations of (absent) self-insight among the incompetent. Organizational Behavior and Human Decision Processess, 105(1), 98-121.

Elenkov, D. S., \& Manev, I. M. (2009). Senior expatriate leadership's effects on innovation and the role of cultural intelligence. Journal of World Business, 44, 357-369.

Engle, R. L., \& Crowne, K. A. (2014). The impact of international experience on cultural intelligence: an application of contact theory in a structured short-term programme. Human Resource Development International, 17(1), 30-46.

Engle, R. L. \& Nash, B. (2016). Foreign travel experience and cultural intelligence: Does country choice matter? Journal of Teaching in International Business, 27(1): 23-40.

EUI. (2015). Academic Careers Observatory, Career Comparisons: Age Comparisons. Available on the internet at

http://www.eui.eu/ProgrammesAndFellowships/AcademicCareersObservatory/CareerCo mparisons/AgeComparisons.aspx Accessed November 18, 2015.

EY. (2013). Global review 2013. Available on the internet at http://www.ey.com/Publication/vwLUAssets/EY_Global_review_2013/\$FILE/EY_Globa 1 review 2013.pdf Accessed August 2, 2018.

Field, A. (2013). Discovering statistics using IBM SPSS statistics (4th edition ed.). Thousand Oaks, CA: Sage.

Flaherty, J. E. (2008). The effects of cultural intelligence on team member acceptance and integration in multinational teams. In S. Ang \& L. Van Dyne (Eds.), Handbook of cultural intelligence: Theory, measurement, and applications (pp. 192-205). New York: M.E. Sharpe.

Flynn, F. J. (2005). Having an open mind: The impact of openness to experience on interracial attitudes and impression formulation. Journal of Personality and Social Psychology, $88(5), 816-826$.

GAA. (2016). Minority report. Available on the internet at http://www.gaaaccounting.com/page/3/ Accessed October 6, 2016. 
Geiger, M. A., \& O'Connell, B. T. (2000). An examination of using surrogate measures to assess social desirability bias. Research on Accounting Ethics, 6, 107-127.

Gelfand, M. J., Imai, L., \& Fehr, R. (2008). Thinking intelligently about cultural intelligence: The road ahead. In S. Ang \& L. Van Dyne (Eds.), Handbook of cultural intelligence: Theory, measurement, and applications (pp. 375-387). New York: M.E. Sharpe.

Gokulsing, K. M. (2006). Without prejudice: An exploration of religious diversity, secularism and citizenship in England (with particular reference to the state funding of Muslim faith schools and multiculturalism). Journal of Educational Policy, 21(4), 459-470.

Gribble, K., \& Ziguras, C. (2003). Learning to teach offshore: Pre-departure training for lecturers in transnational programs. Higher Education Research \& Development, 22(2), 205-216.

Griffer, M. R., \& Perlis, S. M. (2007). Developing cultural intelligence in preservice speechlanguage pathologists and educators. Communication Disorders Quarterly, 29(1), 28-35.

Groves, K. S., Feyerherm, A., \& Gu, M. (2015). Examining cultural intelligence and crosscultural negotiation effectiveness. Journal of Management Education, 39(2), 209-243.

Groves, K. S., \& Feyerherm, A. E. (2011). Leader cultural intelligence in context: Testing the moderating effects of team cultural diversity on leader and team performance. Group \& Organization Management, 36(5), 535-566.

Guthrie, J., \& Parker, L. D. (2014). The global accounting academic: what counts! Accounting, Auditing \& Accountability Journal, 27(1), 2-14.

Hair, J. F., Black, W. C., Babin, B. J., \& Anderson, R. E. (2010). Multivariate data analysis ((7th ed.) ed.). Upper Saddle River, NJ: Pearson Prentice Hall.

Hampden-Turner, C., \& Trompenaars, F. (2006). Cultural Intelligence: Is such a capacity credible? Group \& Organization Management, 31(1), 56-63.

Hancock, P., Howieson, B., Kavanagh, M., Kent, J., Tempone, I., \& Segal, N. (2009). Accounting for the future: more than numbers. A collaborative investigation into the changing skill set for professional accounting graduates over the next ten years and strategies for embedding such skills into professional accounting programs. Sydney: Australian Learning and Teaching Council.

Harrison, N. (2012). Investigating the impact of personality and early life experiences on intercultural interaction in internationalised universities. International Journal of Intercultural Relations, 36(2), 224-237.

Higher Education Academy. (2017). Are you TEF ready? The Teaching Excellence Framework. Available on the internet at https://www.heacademy.ac.uk/institutions/consultancy/TEF?utm source $=$ Google $\% 20 \% 2$ $\underline{\text { 8Grant } \% 29 \& u t m \_ \text {medium }=\text { PPC\&utm campaign }=\text { Consultancy\&gclid=COr5objdtNMCF }}$ Y4EKgodN5cBvw Accessed April 21, 2017.

Hofstede, G., Hofstede, G. J., \& Minkov, M. (2010). Cultures and organizations: Software of the mind: Intercultural cooperation and its importance for survival ((3rd ed.) ed.). New York: McGraw-Hill.

House, R. J., Hanges, P. J., Javidan, M., Dorfman, P. W., \& Gupta, V. (2004). Culture, leadership, and organizations: The GLOBE study of 62 societies. Thousand Oaks, CA: Sage.

Hu, L., \& Bentler, P. M. (1999). Cutoff criteria for fit indexes in covariance structure analysis: Conventional criteria versus new alternatives. Structural Equation Modeling, 6(1), 1-55.

Huang, G., Fowler, C. J., \& Baskerville, R. F. (2016). Entering the accounting profession: the operationalization of ethnicity-based discrimination. Accounting, Auditing \& Accountability Journal, 29(8), 1342-1366. 
ICAEW. (2015a). Culturally intelligent leadership: essential concepts to effectively lead and manage cultural interactions. Available on the internet at http://www.icaew.com/en/library/library-collection/ebooks/countryguides\#sthash.1OklvYa6.dpuf Accessed October 5, 2015.

ICAEW. (2015b). Debating corporate culture: Whose culture is it anyway? Available on the internet at https://www.icaew.com/-/media/corporate/files/technical/audit-andassurance/audit-quality/audit-quality-forum/aqf-whose-culture-is-it-anyway/aqf-nov2015-event-final-article.ashx?la=en Accessed March 20, 2017.

ICEF Monitor. (2017). Cultural experience the big driver of study abroad for Generation Z. Available on the internet at http://monitor.icef.com/2017/02/cultural-experience-bigdriver-study-abroad-generation-z/ Accessed April 18, 2017.

IIE. (2015). Open Doors 2015: Report on international education exchange. Available on the internet at http://www.iie.org/ Accessed November 18, 2015.

Joy, S., \& Kolb, D. A. (2009). Are there cultural differences in learning style? International Journal of Intercultural Relations, 33(1), 69-85.

Kelly, P. (2008). Achieving desirable group-work outcomes through the group allocation process. Team Performance Management: An International Journal, 14(1/2), 22-38.

Keung, E. K., \& Rockinson-Szapkiw, A. J. (2013). The relationship between transformational leadership and cultural intelligence: A study of international school leaders. Journal of Educational Administration, 51(6), 836-854.

Kim, K., Kirkman, B. L., \& Chen, G. (2008). Cultural intelligence and international assignment effectiveness: A conceptual model and preliminary findings. In S. Ang \& L. V. Dyne (Eds.), Handbook of cultural intelligence: Theory, measurement, and applications (pp. 71-90). New York: M. E. Sharpe.

Kline, P. (1999). The handbook of psychological testing ((2nd ed.) ed.). London: Routledge.

KPMG. (2012). Australia in the Asian century: Opportunities and challenges. Available on the internet at

http://www.kpmg.com/AU/en/IssuesAndInsights/ArticlesPublications/Documents/austral ia-in-the-asian-century-opportunities-challenges.pdf Accessed January 5, 2015.

Kruger, J., \& Dunning, D. (1999). Unskilled and unaware of it: How difficulties in recognizing one's own incompetence lead to inflated self-assessments. Journal of Personality and Social Psychology, 77(6), 1121-1134.

Le Roux, J. (2001). Social dynamics of the multinational classroom. Intercultural Education, 12(3), 273-288.

Lee, L.-Y., \& Sukoco, B. M. (2010). The effects of cultural intelligence on expatriate performance: The moderating effects of international experience. International Journal of Human Resource Management, 21(7), 963-981.

Lin, Y.-C., Chen, A. S.-Y., \& Song, Y.-C. (2012). Does your intelligence help to survive in a foreign jungle? The effects of cultural intelligence and emotional intelligence on crosscultural adjustment. International Journal of Intercultural Relations, 36(4), 541-552.

Livermore, D. (2011). The cultural intelligence difference: Master the one skill you can't do without in today's global economy. New York, NY: AMACOM.

Mabe, P. A., \& West, S. G. (1982). Validity of self-evaluation of ability: A review and metaanalysis. Journal of Applied Psychology, 67(3), 280-296.

MacNab, B., \& Worthley, R. (2012). Individual characteristics as predictors of cultural intelligence development: The relevance of self-efficacy. International Journal of Intercultural Relations, 36(1), 62-71. 
Matsumoto, D., \& Hwang, H. C. (2013). Assessing cross-cultural competence: A review of available tests. Journal of Cross-Cultural Psychology, 44(6), 849-873.

Mayer, J. D., Salovey, P., \& Caruso, D. R. (2004). Emotional intelligence: Theory, findings, and implications. Psychological Inquiry, 15(3), 197-215.

McCall, M. W., \& Hollenbeck, G. P. (2002). Developing global executives: The lessons of international experience. Boston, MA: Harvard Business School Press.

McCrae, R. R. (1996). Social consequences of experiential openness. Psychological Bulletin, 120(3), 323-337.

McPhail, K. (2004). An emotional response to the state of accounting education: Developing accounting students' emotional intelligence. Critical Perspectives on Accounting, 15(4-5), 629-648.

Moon, H. K., Choi, B. K., \& Jung, J. S. (2012). Previous international experience, cross-cultural training, and expatriates' cross-cultural adjustment: Effects of cultural intelligence and goal orientation. Human Resource Development Quarterly, 23(3), 285-330.

Moon, T. (2010). Emotional intelligence correlates of the four-factor model of cultural intelligence. Journal of Managerial Psychology, 25(8), 876-898.

Ng, K.-Y., \& Earley, P. C. (2006). Culture + Intelligence: Old constructs, new frontiers. Group \& Organization Management, 31(1), 4-19.

Ng, K.-Y., Van Dyne, L., \& Ang, S. (2012). Cultural intelligence: A review, reflections, and recommendations for future research. In A. M. Ryan, F. T. L. Leong, \& F. L. Oswald (Eds.), Conducting multinational research: Applying organizational psychology in the workplace (pp. 29-58). Washington, DC: American Psychological Association.

Nicholls, S., Wegener, M., Bay, D., \& Cook, G. L. (2012). Emotional intelligence tests: Potential impacts on the hiring process for accounting students. Accounting Education, 21(1), 7595.

O’Connell, B., Carnegie, G., Carter, A., Helliar, C., Watty, K., Hancock, P., \& DeLange, P. (2015). Shaping the future of accounting in business education in Australia, Final Report, July, CPA Australia, Melbourne, Victoria. ISBN: 978-1-921742-67-5. Available on the internet at

https://www.cpaaustralia.com.au/ /media/corporate/allfiles/document/professionalresources/education/shaping-the-future-final-report.pdf?la=en Accessed May 29. 2017.

Oddou, G., Mendenhall, M., \& Ritchie, J. B. (2000). Leveraging travel as a tool for global leadership development. Human Resource Management, 39(2 \& 3), 159-172.

Ones, D. S., \& Viswesvaran, C. (1997). Personality determinants in the prediction of aspects of expatriate job success. In Z. Aycan (Ed.), New approaches to employee management, Vol. 4: Expatriate management: Theory and research (pp. 63-92). Greenwich, CT: JAI Press.

Oolders, T., Chernyshenko, O. S., \& Stark, S. (2008). Cultural Intelligence as a mediator of relationships between openness to experience and adaptive performance. In S. Ang \& L. V. Dyne (Eds.), Handbook of cultural intelligence: Theory, measurement, and applications (pp. 145-158). New York: M.E. Sharpe.

Osland, J. S., \& Osland, A. (2006). Expatriate paradoxes and cultural involvement. International Studies of Management \& Organization, 35(4), 91-114.

Ott, D. L., \& Michailova, S. (2016). Cultural intelligence: A review and new research avenues. International Journal of Management Reviews, 00, 1-21.

Puccino, S. (2007). Worldwide practices and trends in expatriate compensation and benefits. Benefits \& Compensation Digest, 44(1), 34-38. 
Rachman, G. (2017). Trump, Putin, Xi and the rise of nostalgic nationalism. Financial Times, January 2. Available on the internet at https://www.ft.com/content/198efe 76-ce8b-11e6b8ce-b9c03770f8b1 Accessed April 18, 2017.

Ramalu, S. S., Rose, R. C., Kumar, N., \& Uli, J. (2010). Doing business in global arena: An examination of the relationship between cultural intelligence and cross-cultural adjustment. Asian Academy of Management Journal, 15(1), 79-97.

Rockstuhl, T., Seiler, S., Ang, S., Van Dyne, L., \& Annen, H. (2011). Beyond general intelligence (IQ) and emotional intelligence (EQ): The role of cultural intelligence (CQ) on cross-border leadership effectiveness in a globalized world. Journal of Social Issues, 67(4), 825-840.

Rogelberg, S. G., \& Stanton, J. M. (2007). Introduction: Understanding and dealing with organizational survey nonresponse. Organizational Research Methods, 10(2), 195-209.

Sahin, F., Gurbuz, S., \& Koksal, O. (2014). Cultural intelligence (CQ) in action: The effects of personality and international assignment on the development of CQ. International Journal of Intercultural Relations, 39, 152-163.

Samkin, G., \& Schneider, A. (2014). Using university websites to profile accounting academics and their research output. Meditari Accountancy Research, 22(1), 77-106.

Shannon, L. M., \& Begley, T. M. (2008). Antecedents of the four-factor model of cultural intelligence. In S. Ang \& L. V. Dyne (Eds.), Handbook of cultural intelligence: Theory, measurement, and applications (pp. 41-55). New York: M.E. Sharpe.

Shenkar, O. (2012). Beyond cultural distance: Switching to a friction lens in the study of cultural differences. Journal of International Business Studies, 43(1): 12-17.

Shokef, E., \& Erez, M. (2008). Cultural intelligence and global identity in multicultural teams. In S. Ang \& L. V. Dyne (Eds.), Handbook of cultural intelligence: Theory, measurement, and applications (pp. 177-191). New York: M.E. Sharpe.

Spence, C., \& Carter, C. (2014). An exploration of the professional habitus in the Big 4 accounting firms. Work, Employment \& Society, 28(6), 946-962.

Spencer-Rogers, J. (2001). Consensual and individual sterotypic beliefs about international students among American host nationals. International Journal of Intercultural Relations, 25(6), 639-657.

Sternberg, R. J., \& Detterman, D. K. (1986). What is intelligence? Contemporary viewpoints on its nature and definition. Norwood, NJ: Ablex.

Tadros, E., \& King, A. (2014). Australian students turn away from accounting. Financial Review, February 12. Available on the internet at http://www.afr.com/p/national/professional_services/australian students turn away fro m JUUM9mWEp03im4Qk8VEPVI Accessed August 2, 2018.

Takeuchi, R., Tesluk, P. E., Yun, S., \& Lepak, D. P. (2005). An integrative view of international experience. Academy of Management Journal, 48(1), 85-100.

Tan, J.-S. (2004). Cultural intelligence and the global economy. Leadership in Action, 24(5), 1921.

Tange, H., \& Jensen, I. (2012). Good teachers and deviant learners? The meeting of practices in university level international education. Journal of Research in International Education, 11(2), 181-193.

Tarique, I., \& Takeuchi, R. (2008). Developing cultural intelligence: The roles of international nonwork experiences. In S. Ang \& L. Van Dyne (Eds.), Handbook of cultural intelligence: Theory, measurement, and applications (pp. 56-70). New York: M.E. Sharpe. 
Tay, C., Westman, M., \& Chia, A. (2008). Antecedents and consequences of cultural intelligence among short-term business travelers. In S. Ang \& L. V. Dyne (Eds.), Handbook of cultural intelligence: Theory, measurement, and applications (pp. 126-144). New York: M.E. Sharpe.

Teekens, H. (2003). The requirement to develop specific skills for teaching in an international setting. Journal of Studies in International Education, 7(1), 108-119.

Tomalin, E. (2007). Supporting cultural and religious diversity in higher education: Pedagogy and beyond. Teaching in Higher Education, 12(5-6), 621-634.

Triandis, H. C. (2006). Cultural intelligence in organizations. Group \& Organization Management, 31(1), 20-26.

Universities Australia. (2017). International student numbers surge to record high. Media Release, February 22, 2017. Available on the internet at https://www.universitiesaustralia.edu.au/Media-and-Events/media-releases/Internationalstudent-numbers-surge-to-record-high\#.WPXM fmGOUk Accessed April 18, 2017.

Universities UK. (2017). The economic impact of international students. March, 2017. Available on the internet at http://www.universitiesuk.ac.uk/policy-andanalysis/reports/Documents/2017/briefing-economic-impact-international-students.pdf Accessed April 18, 2017.

Van Dyne, L., Ang, S., \& Koh, C. (2008). Development and validation of the CQS: The cultural intelligence scale. In S. Ang \& L. V. Dyne (Eds.), Handbook of cultural intelligence: Theory, measurement, and applications (pp. 16-40). New York: M. E. Sharpe.

Van Dyne, L., Ang, S., \& Livermore, D. (2010). Cultural intelligence: A pathway for leading in a rapidly globalizing world. In K. Hannum, B. B. McFeeters, \& L. Booysen (Eds.), Leading across differences (pp. 131-138). San Francisco, CA: Pfeiffer.

Van Dyne, L., Ang, S., Ng, K.-Y., Rockstuhl, T., Tan, M. L., \& Koh, C. (2012). Sub-dimensions of the four factor model of cultural intelligence: Expanding the conceptualization and measurement of cultural intelligence. Social and Personality Psychology Compass, 6(4), 295-313.

Ward, C., Fischer, R., Lam, F. S. Z., \& Hall, L. (2009). The convergent, discriminant, and incremental validity of scores on a self-report measure of cultural intelligence. Educational and Psychological Measurement, 69, 85-105.

Wood, E. D., \& St. Peters, H. Y. Z. (2013). Short-term cross-cultural study tours: Impact on cultural intelligence. International Journal of Human Resource Management, 25(4), 558570.

Wu, P., \& Ang, S. H. (2011). The impact of expatriate supporting practices and cultural intelligence on cross-cultural adjustment and performance of expatriates in Singapore. International Journal of Human Resource Management, 22(13), 2683-2702.

Yang, H. H. (2012). Western concepts, Chinese context: A note on teaching accounting offshore. International Journal of Pedagogies and Learning, 7(1), 20-30.

Zhang, Y. \& Oczkowski, E. (2016). Exploring the potential effects of expatriate adjustment direction. Cross Cultural \& Strategic Management, 23(1): 158-183. 
Figure 1: The four component theoretical framework of $C Q$

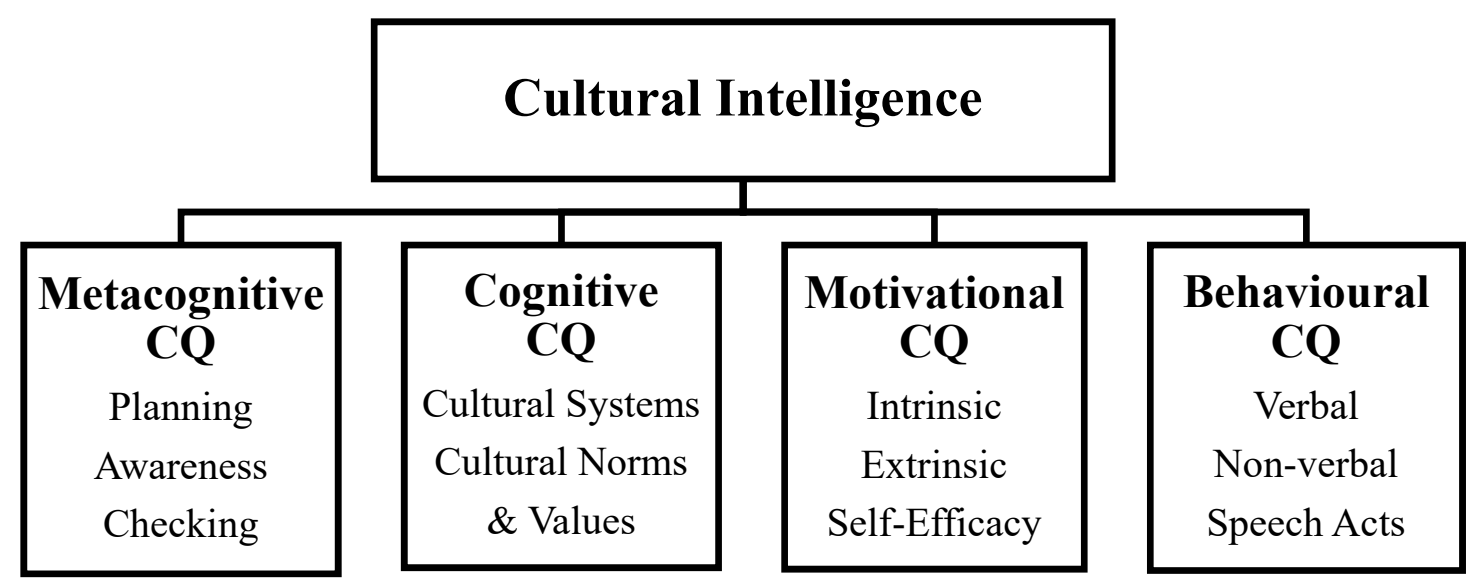

Source: Adapted from Van Dyne, Ang, and Livermore (2010) 
Table 1: Demographics of respondents

\begin{tabular}{|c|c|c|}
\hline & $\begin{array}{l}\text { No of responses } \\
N=253\end{array}$ & $\%$ of responses \\
\hline \multicolumn{3}{|c|}{ University Location (CityUni) } \\
\hline City & 224 & 88.5 \\
\hline Regional & 29 & 11.5 \\
\hline \multicolumn{3}{|l|}{ Gender } \\
\hline Female & 118 & 46.6 \\
\hline Male & 135 & 53.4 \\
\hline \multicolumn{3}{|l|}{ Age } \\
\hline Under 35 years & 42 & 16.6 \\
\hline $35-44$ years & 42 & 16.6 \\
\hline $45-54$ years & 96 & 37.9 \\
\hline 55 years or over & 73 & 28.9 \\
\hline \multicolumn{3}{|l|}{ Academic position } \\
\hline Associate Lecturer & 30 & 11.9 \\
\hline Lecturer & 103 & 40.7 \\
\hline Senior Lecturer & 45 & 17.8 \\
\hline Associate Professor & 24 & 9.5 \\
\hline Professor & 36 & 14.2 \\
\hline Other & 15 & 5.9 \\
\hline \multicolumn{3}{|c|}{ Tertiary teaching experience (TeachExp) } \\
\hline Under 2 years & 11 & 4.3 \\
\hline $2-4$ years & 23 & 9.1 \\
\hline $5-10$ years & 55 & 21.7 \\
\hline $11-15$ years & 41 & 16.2 \\
\hline More than 15 years & 123 & 48.6 \\
\hline \multicolumn{3}{|c|}{ Formal teaching qualification } \\
\hline Yes & 86 & 34.0 \\
\hline No & 167 & 66.0 \\
\hline \multicolumn{3}{|c|}{ Number of times taught offshore } \\
\hline 0 & 84 & 33.2 \\
\hline $1-3$ & 56 & 22.1 \\
\hline $4-10$ & 36 & 14.2 \\
\hline More than 10 & 77 & 30.4 \\
\hline \multicolumn{3}{|c|}{ Countries taught offshore (TaughtOffshore) } \\
\hline 0 & 83 & 32.8 \\
\hline 1 & 45 & 17.8 \\
\hline $2-3$ & 78 & 30.8 \\
\hline $4-5$ & 33 & 13.0 \\
\hline More than 5 & 14 & 5.5 \\
\hline \multicolumn{3}{|l|}{ English first Language } \\
\hline Yes & 183 & 72.3 \\
\hline No & 70 & 27.7 \\
\hline \multicolumn{3}{|c|}{ Languages spoken other than English (LangSpoken) } \\
\hline None & 145 & 57.3 \\
\hline 1 & 69 & 27.3 \\
\hline 2 & 31 & 12.3 \\
\hline 3 & 5 & 2.0 \\
\hline More than 3 & 3 & 1.2 \\
\hline \multicolumn{3}{|c|}{ Residency in another country (OverseasRes) } \\
\hline Yes & 138 & 54.5 \\
\hline No & 115 & 45.5 \\
\hline
\end{tabular}


Table 2: CQ component scores

\begin{tabular}{lllll}
\hline Calculation description & CQ Component & Mean (SD) & Min & Max \\
\hline 4 component average & Total CQ & $4.98(0.83)$ & 1.55 & 7.00 \\
4 item average & Metacognitive & $5.34(0.97)$ & 1.25 & 7.00 \\
6 item average & Cognitive & $4.19(1.14)$ & 1.00 & 7.00 \\
5 item average & Motivational & $5.33(0.95)$ & 1.20 & 7.00 \\
5 item average & Behavioural & $5.06(0.96)$ & 1.60 & 7.00 \\
\hline
\end{tabular}


Table 3: CQ scores for cohorts in prior studies

\begin{tabular}{|c|c|c|c|c|c|c|c|}
\hline & & $\mathbf{N}$ & $\begin{array}{c}\text { Total } \\
\text { CQ } \\
\text { Mean* }\end{array}$ & $\begin{array}{c}\text { Metacognitive } \\
\text { CQ } \\
\text { Mean (SD) } \\
\end{array}$ & $\begin{array}{l}\text { Cognitive } \\
\text { CQ Mean } \\
\text { (SD) }\end{array}$ & $\begin{array}{c}\text { Motivational } \\
\text { CQ } \\
\text { Mean (SD) } \\
\end{array}$ & $\begin{array}{c}\text { Behavioural } \\
\text { CQ } \\
\text { Mean (SD) }\end{array}$ \\
\hline 1 & $\begin{array}{l}\text { International school leaders working } \\
\text { in various countries } \\
\text { (Keung \& Rockinson-Szapkiw, 2013) }\end{array}$ & 193 & 5.76 & $6.03(0.88)$ & $5.00(1.10)$ & $6.25(0.88)$ & $5.75(0.95)$ \\
\hline 2 & $\begin{array}{l}\text { Expatriates working in Malaysia } \\
\text { (Ramalu et al., 2010) }\end{array}$ & 332 & 5.57 & $5.79(0.69)$ & $5.16(0.56)$ & $5.90(0.71)$ & $5.42(0.81)$ \\
\hline 3 & $\begin{array}{l}\text { Multicultural team members based in } \\
\text { various countries } \\
\text { (Flaherty, 2008) }\end{array}$ & 51 & 5.38 & $5.70(0.74)$ & $4.69(0.99)$ & $5.98(0.66)$ & $5.16(0.96)$ \\
\hline 4 & $\begin{array}{l}\text { Koreans expatriated overseas } \\
\text { (H. K. Moon et al., 2012) }\end{array}$ & 190 & 5.16 & $5.37(0.79)$ & $4.75(0.92)$ & $5.27(0.99)$ & $5.24(0.79)$ \\
\hline 5 & $\begin{array}{l}\text { International Managers } \\
\text { (17 nations) } \\
\text { (Ang et al., 2007) }\end{array}$ & 98 & 5.00 & $5.41(0.78)$ & $3.80(1.03)$ & $5.82(0.75)$ & $4.98(0.99)$ \\
\hline 6 & $\begin{array}{l}\text { Graduate \& Undergraduate Students } \\
\text { (Ireland) } \\
\text { (Shannon \& Begley, 2008) }\end{array}$ & 245 & 4.98 & $5.21(0.90)$ & $3.85(1.01)$ & $5.85(0.80)$ & $5.02(0.97)$ \\
\hline 7 & Australian Accounting Academics & 253 & 4.98 & $5.34(0.97)$ & $4.19(1.14)$ & $5.33(0.95)$ & $5.06(0.96)$ \\
\hline 8 & $\begin{array}{l}\text { Philippine labourers working in } \\
\text { Taiwan } \\
\text { (Chen et al., 2011) }\end{array}$ & 382 & 4.76 & $4.96(1.00)$ & $4.30(1.18)$ & $4.85(1.05)$ & $4.91(1.03)$ \\
\hline 9 & $\begin{array}{l}\text { International University Students } \\
\text { (Taiwan) } \\
\text { (Lin et al., 2012) }\end{array}$ & 295 & 4.72 & $4.95(0.88)$ & $4.23(0.96)$ & $4.83(0.88)$ & $4.88(0.84)$ \\
\hline 10 & $\begin{array}{l}\text { Turkish military personnel } \\
\text { (Sahin et al., 2014) }\end{array}$ & 145 & 4.72 & $4.93(1.49)$ & $3.93(1.30)$ & $5.22(1.50)$ & $4.80(1.37)$ \\
\hline 11 & $\begin{array}{l}\text { Undergraduate Students } \\
\text { (US) } \\
\text { (Van Dyne et al., 2008) }\end{array}$ & 337 & 4.55 & $4.98(0.95)$ & $3.66(0.98)$ & $5.34(0.94)$ & $4.20(1.14)$ \\
\hline 12 & $\begin{array}{l}\text { US professionals/part-time MBA } \\
\text { students } \\
\text { (Wood \& St. Peters, 2013) }\end{array}$ & 42 & 4.50 & $4.80(1.24)$ & $3.36(1.18)$ & $5.12(1.16)$ & $4.70(1.28)$ \\
\hline 13 & $\begin{array}{l}\text { US team leaders/part-time MBA } \\
\text { students } \\
\text { (Groves \& Feyerherm, 2011) }\end{array}$ & 99 & 4.40 & $4.91(1.21)$ & $3.32(1.38)$ & $5.06(1.19)$ & $4.29(1.34)$ \\
\hline 14 & $\begin{array}{l}\text { Graduate \& Undergraduate Students } \\
\text { (Korea) } \\
\text { (T. Moon, 2010) }\end{array}$ & 381 & 3.90 & $3.25(1.29)$ & $3.21(1.31)$ & $4.50(1.54)$ & $4.65(1.48)$ \\
\hline 15 & $\begin{array}{l}\text { Undergraduate Students } \\
\text { (New Zealand) } \\
\text { (Oolders et al., 2008) }\end{array}$ & 311 & 3.41 & $3.51(0.62)$ & $2.71(0.70)$ & $3.85(0.67)$ & $3.58(0.57)$ \\
\hline
\end{tabular}

*SD for Total CQ not available for other studies 
Table 4: Pearson correlations between variables examined in the study

\begin{tabular}{|c|c|c|c|c|c|c|c|c|c|c|c|c|c|}
\hline & $\begin{array}{c}\text { MET } \\
\mathrm{CQ}\end{array}$ & $\begin{array}{c}\mathrm{COG} \\
\mathrm{CQ}\end{array}$ & $\begin{array}{c}\text { MOT } \\
\text { CQ }\end{array}$ & $\begin{array}{c}\mathrm{BEH} \\
\mathrm{CQ}\end{array}$ & $\begin{array}{c}\text { Total } \\
\mathrm{CQ}\end{array}$ & CityUni & Gender & Age & $\begin{array}{l}\text { Teach } \\
\text { Exp }\end{array}$ & $\begin{array}{c}\text { Lang } \\
\text { Spoken }\end{array}$ & $\begin{array}{c}\text { Taught } \\
\text { Offshore } \\
\text { (Asia) }\end{array}$ & $\begin{array}{l}\text { Taught } \\
\text { Offshore } \\
\text { (Anglo) }\end{array}$ & $\begin{array}{c}\text { Overseas } \\
\text { Res }\end{array}$ \\
\hline \multicolumn{14}{|l|}{ Metacognitive CQ } \\
\hline Cognitive $\mathrm{CQ}$ & $.623^{* \star}$ & & & & & & & & & & & & \\
\hline Motivational CQ & $.599^{\star \star}$ & $.593^{\star \star}$ & & & & & & & & & & & \\
\hline Behavioural CQ & $.661^{\star *}$ & $.465^{* \star}$ & $.540^{\star \star}$ & & & & & & & & & & \\
\hline Total CQ & $.867^{\star *}$ & $.828^{* *}$ & $.820^{\star *}$ & $.794^{\star \star}$ & & & & & & & & & \\
\hline CityUni & -.061 & -.115 & -.054 & $-.135^{*}$ & -.112 & & & & & & & & \\
\hline Gender & .052 & -.008 & -.036 & .102 & .032 & -.012 & & & & & & & \\
\hline Age & .078 & .078 & $.126^{*}$ & .061 & .103 & -.122 & -.064 & & & & & & \\
\hline TeachExp & -.039 & -.038 & -.021 & -.027 & -.038 & -.072 & $-.180^{\star *}$ & $.535^{* *}$ & & & & & \\
\hline LangSpoken & .097 & $.199^{* *}$ & .021 & $.126^{*}$ & $.139^{*}$ & .035 & -.006 & $-.240^{* *}$ & $-.200^{\star *}$ & & & & \\
\hline TaughtOffshore(Asia) & .112 & $.192^{* *}$ & $.170^{* *}$ & .106 & $.178^{* *}$ & $-.129^{*}$ & $-.213^{* *}$ & $.267^{\star *}$ & $.396^{* *}$ & -.063 & & & \\
\hline TaughtOffshore(Anglo) & .011 & $.180^{* *}$ & .064 & -.012 & .080 & $-.281^{* *}$ & $-.125^{*}$ & $.219^{* *}$ & $.252^{* \star}$ & -.102 & $.245^{* *}$ & & \\
\hline OverseasRes & $.212^{\star *}$ & $.239^{* *}$ & .123 & $.148^{*}$ & $.222^{* *}$ & -.005 & -.054 & -.037 & -.065 & $.419^{* *}$ & .012 & $.226^{* *}$ & \\
\hline
\end{tabular}

${ }^{*}$ Correlation is significant at the 0.01 level (2-tailed)

* Correlation is significant at the 0.05 level (2-tailed)

\section{Summary of variables}

CityUni

Gender

Age

TeachExp

LangSpoken

TaughtOffshore(Asia)

TaughtOffshore(Anglo)

OverseasRes employed at university located in State or Territory capital city $=1,0$ otherwise

female $=1$, male $=0$

45 years of age and over $=1,0$ otherwise

more than 15 years tertiary teaching experience $=1,0$ otherwise

1 or more languages (apart from English) spoken fluently $=1,0=$ none

taught offshore in Singapore, Hong Kong, Malaysia or mainland China $=1,0$ otherwise

taught offshore in UK, US, Canada or New Zealand $=1,0$ otherwise

resided overseas for a continuous period exceeding 12 months: yes $=1$, no $=0$ 
Table 5: Results of OLS Regression on CQ determinants $(n=253)$

\begin{tabular}{|c|c|c|c|c|c|c|c|c|c|c|c|c|c|c|c|c|}
\hline & \multirow{2}{*}{$\begin{array}{l}\text { Exp } \\
\text { Sign }\end{array}$} & \multicolumn{3}{|c|}{ Total CQ } & \multicolumn{3}{|c|}{ Metacognitive CQ } & \multicolumn{3}{|c|}{ Cognitive CQ } & \multicolumn{3}{|c|}{ Motivational CQ } & \multicolumn{3}{|c|}{ Behavioural CQ } \\
\hline & & Beta & $\mathrm{t}$ & Sig. & Beta & $\mathrm{t}$ & Sig. & Beta & $\mathrm{t}$ & Sig. & Beta & $t$ & Sig. & Beta & $\mathrm{t}$ & Sig. \\
\hline (Constant) & & 4.651 & 22.244 & $0.000 * * *$ & 4.990 & 20.006 & $0.000 * * *$ & 3.650 & 12.933 & $0.000 * * *$ & 5.028 & 20.453 & $0.000 * * *$ & 4.936 & 20.101 & $0.000 * * *$ \\
\hline CityUni & $+/-$ & -.213 & -1.299 & 0.195 & -.169 & -.861 & 0.390 & -.201 & -.909 & 0.364 & -.071 & -.371 & 0.711 & -.411 & -2.135 & 0.034 ** \\
\hline Gender & $+/-$ & .106 & 1.030 & 0.304 & .140 & 1.134 & 0.258 & .081 & .584 & 0.560 & -.025 & -.202 & 0.840 & .229 & 1.888 & 0.060 * \\
\hline Age & + & .284 & 2.221 & 0.014 ** & .267 & 1.746 & $0.041^{* *}$ & .315 & 1.826 & $0.035^{* *}$ & .351 & 2.334 & $0.010^{* *}$ & .204 & 1.355 & 0.088 * \\
\hline TeachExp & + & -.284 & -2.249 & $0.013^{* *}$ & -.237 & -1.575 & 0.058 * & -.400 & -2.348 & $0.010^{* *}$ & -.354 & -2.383 & $0.009 * * *$ & -.145 & -.977 & 0.165 \\
\hline LangSpoken & + & .135 & 1.159 & 0.124 & .027 & .191 & 0.424 & .382 & 2.434 & $0.008^{* * *}$ & -.027 & -.199 & 0.421 & .158 & 1.154 & 0.125 \\
\hline TaughtOffshore(Asia) & + & .352 & 3.148 & $0.001^{* * *}$ & .295 & 2.209 & $0.014 * *$ & .471 & 3.121 & $0.001^{* * *}$ & .367 & 2.785 & $0.003 * * *$ & .277 & 2.104 & $0.018 * *$ \\
\hline TaughtOffshore(Anglo) & + & -.027 & -.199 & 0.421 & -.185 & -1.139 & 0.128 & .328 & 1.782 & $0.038 * *$ & -.029 & -.179 & 0.429 & -.222 & -1.390 & $0.083 *$ \\
\hline OverseasRes & + & .310 & 2.681 & $0.004^{* * *}$ & .434 & 3.144 & $0.001^{* * *}$ & .307 & 1.966 & $0.025 * *$ & .235 & 1.728 & $0.043^{* *}$ & .265 & 1.950 & 0.026 ** \\
\hline$F$-value & & 4.290 & & $.000^{* * *}$ & 2.895 & & $.004^{* * *}$ & 5.375 & & $.000^{* * *}$ & 2.456 & & .014 ** & 2.876 & & $.004^{* * *}$ \\
\hline$R^{2}$ & & 0.123 & & & 0.087 & & & 0.150 & & & 0.075 & & & 0.086 & & \\
\hline Adjusted $R^{2}$ & & 0.095 & & & 0.057 & & & 0.122 & & & 0.044 & & & 0.056 & & \\
\hline
\end{tabular}

${ }^{*} p<0.10,{ }^{* *} p<0.05,{ }^{* * *} p<0.01$

The Sig levels are one-tail, except for the intercept, CityUni and Gender.

\section{Summary of variables}

CityUni

Gender

Age

TeachExp

LangSpoken

TaughtOffshore(Asia)

TaughtOffshore(Anglo)

OverseasRes

employed at university located in State or Territory capital city $=1,0$ otherwise

female $=1$, male $=0$

45 years of age and over $=1,0$ otherwise

more than 15 years tertiary teaching experience $=1,0$ otherwise

1 or more languages (apart from English) spoken fluently $=1,0=$ none

taught offshore in Singapore, Hong Kong, Malaysia or mainland China $=1,0$ otherwise

taught offshore in UK, US, Canada, and New Zealand $=1,0$ otherwise

resided overseas for a continuous period exceeding 12 months: yes $=1$, no $=0$ 